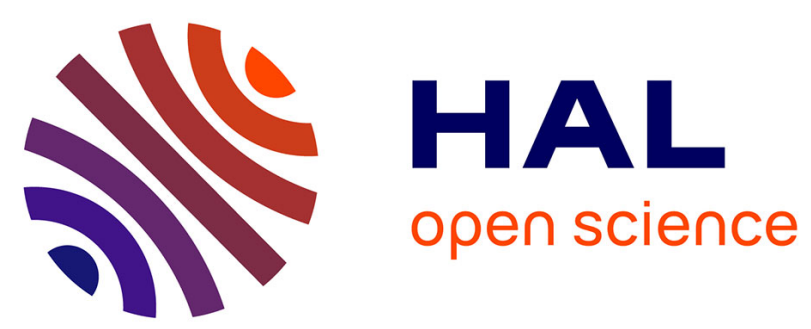

\title{
Climatic precession is the main driver of Early Cretaceous sedimentation in the Vocontian Basin (France): Evidence from the Valanginian Orpierre succession
}

Slah Boulila, G. Charbonnier, Bruno Galbrun, Silvia Gardin

\section{To cite this version:}

Slah Boulila, G. Charbonnier, Bruno Galbrun, Silvia Gardin. Climatic precession is the main driver of Early Cretaceous sedimentation in the Vocontian Basin (France): Evidence from the Valanginian Orpierre succession. Sedimentary Geology, 2015, 324, pp.1-11. 10.1016/j.sedgeo.2015.04.014 . hal01150959

\section{HAL Id: hal-01150959 \\ https://hal.science/hal-01150959}

Submitted on 28 May 2015

HAL is a multi-disciplinary open access archive for the deposit and dissemination of scientific research documents, whether they are published or not. The documents may come from teaching and research institutions in France or abroad, or from public or private research centers.
L'archive ouverte pluridisciplinaire $\mathbf{H A L}$, est destinée au dépôt et à la diffusion de documents scientifiques de niveau recherche, publiés ou non, émanant des établissements d'enseignement et de recherche français ou étrangers, des laboratoires publics ou privés. 


\title{
Climatic precession is the main driver of Early Cretaceous sedimentation in the Vocontian Basin (France): evidence from the Valanginian Orpierre succession
}

\author{
Slah Boulila ${ }^{1,2,}$, Guillaume Charbonnier ${ }^{3}$, Bruno Galbrun ${ }^{1}$, and Silvia Gardin ${ }^{4}$ \\ ${ }^{1}$ UMR-CNRS 7193 ISTeP, Institut des Sciences de la Terre-Paris, Université Pierre et Marie Curie, 4 place \\ Jussieu, 75252 Paris CEDEX 5, France. \\ ${ }_{2}^{2}$ ASD, IMCCE-CNRS UMR 8028, Observatoire de Paris, UPMC, 77 avenue Denfert-Rochereau, 75014 Paris, \\ France \\ ${ }^{3}$ UMR CNRS 8148 IDES, Interactions et Dynamique des Environnements de Surface, Université Paris Sud XI, \\ Bâtiment 504, 91405 Orsay, France. \\ ${ }^{4}$ UMR-CNRS 7072 CR2P, Centre de Recherche sur la Paléobiodiversité et les Paléoenvironnements, Université \\ Pierre et Marie Curie, 4 place Jussieu, 75252 Paris CEDEX 5, France.
}

\section{* Corresponding author:}

Email address: slah.boulila@upmc.fr

Telephone number: 0033 (0) 144274163

Fax number: 0033 (0) 144273831

\begin{abstract}
The Valanginian sediments outcropping in the Vocontian Basin (SE France) exhibit striking marl-limestone alternations, which were formed under the influence of orbital forcing and which have served for geochronological and paleoenvironmental studies. Previous studies have suggested an obliquity forcing during the Late Valanginian interval, reflecting specific environmental conditions such as polar ice. Using a cyclostratigraphic correlation of previously studied sections and performing time-series analysis on the most complete Late Valanginian interval we argue that the climatic precession cycle is the primary driver of these marl-limestone alternations. In addition, we highlight the modulation of the precession by the $\sim 100$ and 405 kyr eccentricity cycles. We suggest that the cyclostratigraphic misinterpretation (i.e., obliquity-forcing hypothesis) results mainly from poorly preserved $405 \mathrm{kyr}$ eccentricity cycles, due to local hiatuses and/or "missed beats". This study shows the potential of cyclostratigraphic correlations for the detection and quantification of differential hiatuses and/or "missed beats" within intrabasinal sequences, hence providing constraints on cyclostratigraphic interpretations. The recorded $405 \mathrm{kyr}$ eccentricity cycle is of prominent amplitude, and controlled the fourth-order sea-level sequences. These latter are faithfully detected through cyclostratigraphically inferred sedimentation rate. Finally, we show that the well-known, pronounced lithostratigraphic markers/intervals in the basin were orbitally paced by the $405 \mathrm{kyr}$ eccentricity extrema. This is a good argument for the strong impact of this cyclicity on the sedimentary processes, especially during greenhouse periods.
\end{abstract}

Keywords: Late Valanginian, Vocontian Basin, SE France, marl-limestone alternations, precession forcing, sea-level change. 


\section{Introduction}

The dominance of obliquity forcing to the detriment of the precession during some Mesozoic events, as the Oceanic Anoxic Events (Huang et al., 2010; Meyers et al., 2012), has stimulated studies to look for such differential expression and its potential implication for paleoenvironmental changes. The Valanginian Stage (Early Cretaceous) is known for significant changes in the global carbon cycle (Erba et al., 2004), and a possible climatic cooling (McArthur et al., 2007).

The Valanginian sequences in the Vocontian Basin (SE France) are characterized by marl-limestone alternations of astroclimatic origin (e.g., Huang et al., 1993; Gréselle and Pittet, 2010). A previous cyclostratigraphic study (Giraud et al., 1995) interpreted the Late Valanginian marl-limestone couplets in the Vocontian Basin as reflecting obliquity cycles. More recently, two high-resolution cyclostratigraphic studies in the Vocontian Basin (Fig. 1, Martinez et al., 2013; Charbonnier et al., 2013) came to opposing conclusions for the Late Valanginian cyclostratigraphy. Charbonnier et al. (2013) demonstrated that the couplets were driven by the precession with a modulation by the eccentricity. Martinez et al. (2013) interpreted the couplets, in the interval spanning the $\mathrm{N}$. peregrinus ammonite zone p.p., as obliquity in origin and discussed possible implication for the existence of polar ice.

In this study, we examine if the assumption of obliquity forcing is correct, first through a detailed correlation between the aforcited sections, then by additional statistical tests applied to the most continuous interval at the Orpierre section. This interval should be used as a typical example for the record of orbital cycles in the Valanginian sequences. In addition, with its high-resolution and -fidelity, this interval permits to resolve the controversial interpretations of the Late Valanginian cyclostratigraphy. Finally, we discussed the implications of our study for climate and sea-level changes, and the strong impact of longperiod orbital cyclicities on the sedimentary processes that makes them well expressed in the outcrops (e.g., 405 kyr eccentricity).

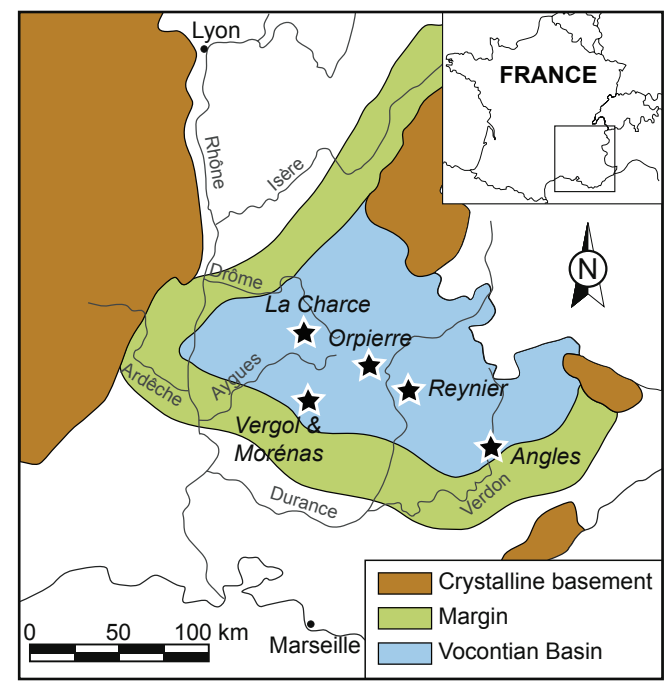

Figure 1: Location of the correlated Valanginian sections (indicated by black stars) in the Vocontian Basin of southeastern France (modified from Martinez, 2013, and Gréselle and Pittet, 2010).

\section{Methods and results}

\subsection{Methods}

Observational gaps and slumps are locally encountered in the Orpierre section (Charbonnier et al., 2013). To overcome this constraint, we focused on the uninterrupted $\sim 100 \mathrm{~m}$ thick interval, bounded by two slumps and spanning the NK3A p.p. and NK3B 
nannofossil zones (which roughly correspond to S. verrucosum and N. peregrinus, ammonite zones; Figs. 2 and 3). We selected this interval for time-series analysis (Fig. 4) and correlation because it is continuously resolved (Figs. 2 and 3, Figs. S1 and S2). The interval was sampled at high-resolution $(\sim 7 \mathrm{~cm})$ for laboratory magnetic susceptibility (MS) measurements (Charbonnier et al., 2013). The equivalent intervals at the Reynier/Angles (RA) and Vergol/Morénas/La Charce (VMC) sections (Figs. 2 and 3) were measured directly in the field for gamma-ray spectrometry (GRS), at a resolution of $\sim 20 \mathrm{~cm}$ (Martinez et al., 2013). Despite the different resolutions adopted in the two studies (Fig. S1) and different sensitivity of the used physical detectors, MS and GRS variations indicate well the clay versus carbonate content variations (Figs. 2 and 3).

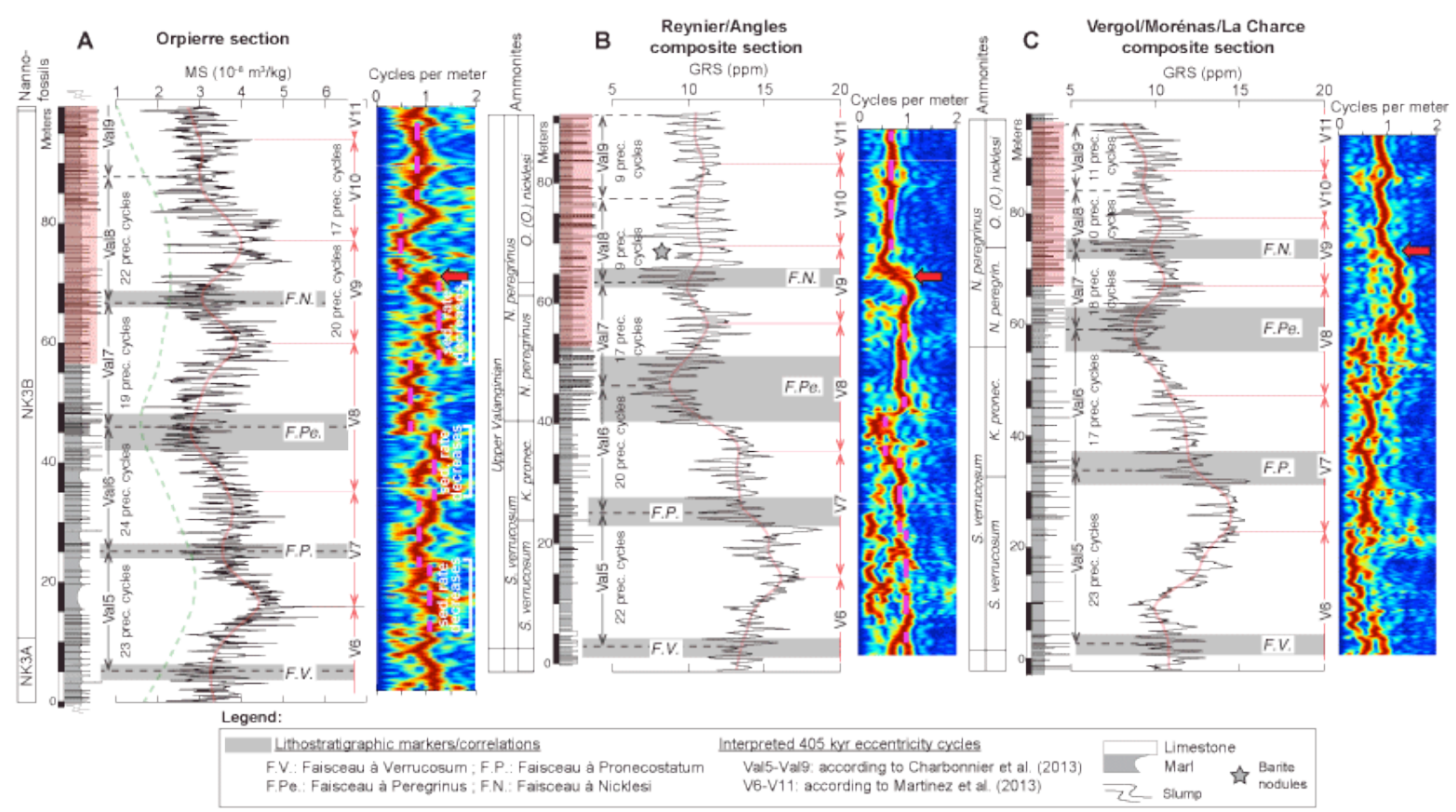

Figure 2: Cyclostratigraphic correlation of the Late Valanginian sections (SE France), and evolutive harmonic analysis (EHA) of the detrended physical proxy data (Val5 to Val9 cycles attributed to the 405 kyr eccentricity are removed) to describe variations in sedimentation rate, expressed through the change in thickness of couplets (i.e., wavelength of precession cycles). (A) Magnetic susceptibility (MS) variations at Orpierre section (from Charbonnier et al., 2013). 12\% and 30\% weighted averages of the series are shown (solid and dashed curves, respectively). (B) Gamma-ray spectrometry (GRS) variations at the Reynier and Angles (RA) composite section (from Martinez et al., 2013). (C) GRS variations at the Vergol, Morénas and La Charce (VMC) composite section (from Martinez et al., 2013). A 10\% weighted average of the series is shown for RA and VMC (orange line). Note that all lithostratigraphic markers, and the $405 \mathrm{kyr}$ cycles V6 to V11 in the RA and VMC sections are placed according to Martinez et al. (2013) (their figure 5). The orange shaded intervals in the three stratigraphic columns, encompassing V9, V10 and V11, corresponds to those in which Martinez et al., 2013 have interpreted the couplets as being related to obliquity. Numbers of precession cycles within each $405 \mathrm{kyr}$ cycle are also shown (see Figs. S2 to S4 for more details). The increase in sedimentation rate in the middle part of V9 cycle, which is pronounced in RA section, is indicated by red arrow in EHA spectrograms. Also, oscillations in sedimentation rate are indicated on the highly resolved Orpierre spectrogram.

For time-series analysis, we first performed spectral analysis (Ghil et al., 2002) on the MS data in the depth domain, then to the $405 \mathrm{kyr}$ tuned data (Fig. 4) assuming that the 18.5 $\mathrm{m}$ wavelength (Section 2.2) corresponds to the $405 \mathrm{kyr}$ eccentricity component (Charbonnier et al., 2013). Also, we performed the tuning at the precession and short eccentricity cycle bands to see if the calibrated long-wavelength $(18.5 \mathrm{~m})$ corresponds to the $405 \mathrm{kyr}$ eccentricity term. We compared the calibrated MS periods to astronomical periods for the Valanginian time (Laskar et al., 2004). We applied amplitude modulation (AM) technique 
conjointly with bandpass and lowpass filtering in order to assess the modulation of the precession by the eccentricity terms. In addition, we performed evolutive harmonic analysis on the untuned data to quantify variations in sedimentation rate. Finally, we focused on the questionable interval spanning V9 to V11 p.p. (Section 2.3) in order to discuss precession vs obliquity controversies of the Late Valanginian.

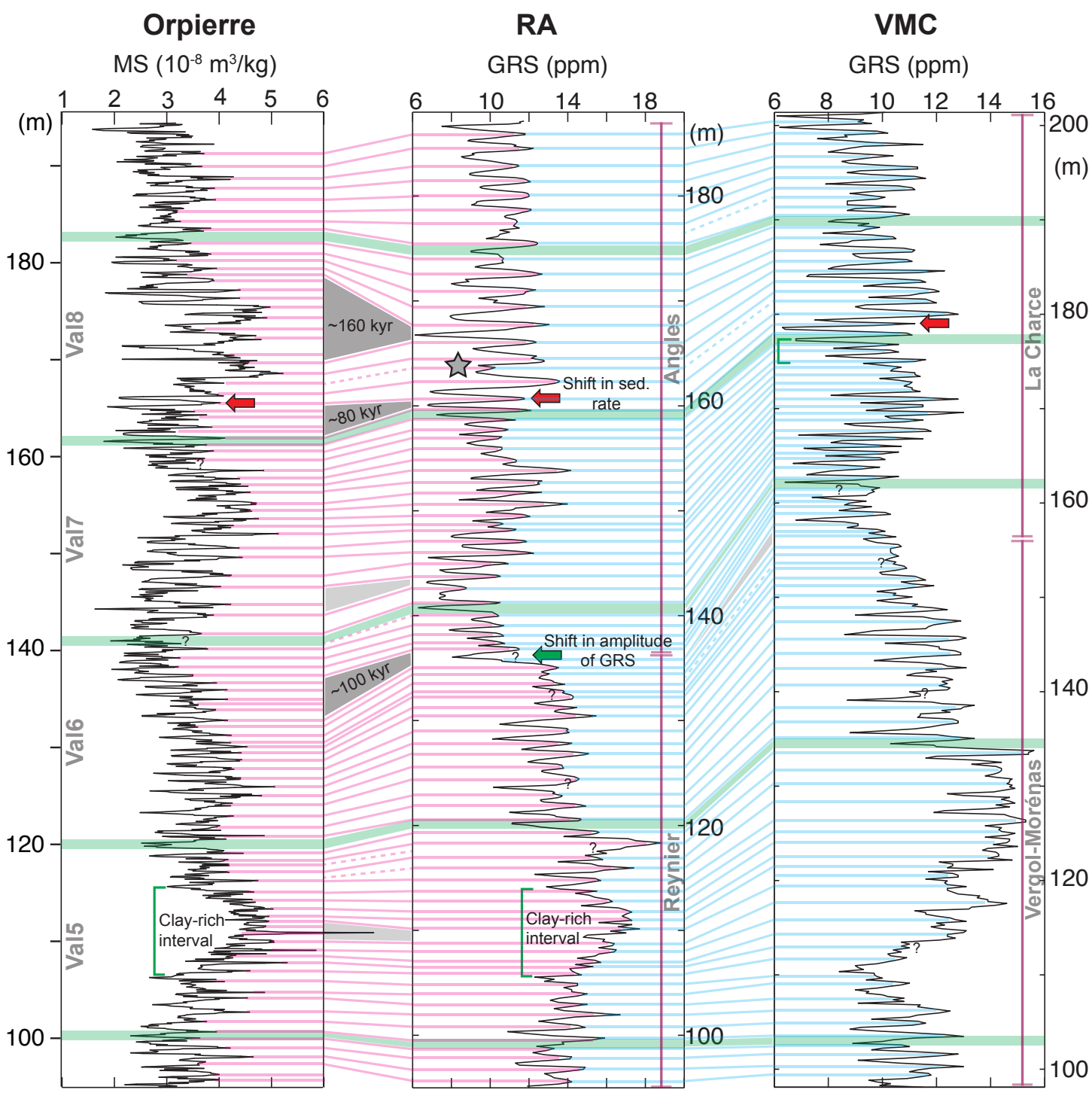

Figure 3: High-resolution cyclostratigraphic correlation, at the scale of precession cycles, between the three studied sections. Hiatuses of durations longer than one precession equivalent cycles are shown by grey-shaded areas: light grey for hiatuses of durations equivalent to two precession cycles, dark grey for hiatuses of durations equal or longer than three precession equivalent cycles. Dashed correlation lines indicate differential record in one precession cycle between sections. Only hiatuses of more than two precession equivalent cycles are considered in the discussion. The level of barite nodules in Angles is indicated by the star.

This correlation allows to slightly shift some boundaries of the $405 \mathrm{kyr}$ related cycles Val5 to Val8, compared to those defined in Figure 2. Upper boundary of Val5 is shifted down by one precession cycle in RA and VMC. Upper boundary of Val6 is shifted down by one precession cycle in RA and VMC. Upper boundary of Val8 is shifted up by one precession cycle in RA and VMC. Question marks indicate uncertainly identified precession cycles (see also Figs. S2-S4). 

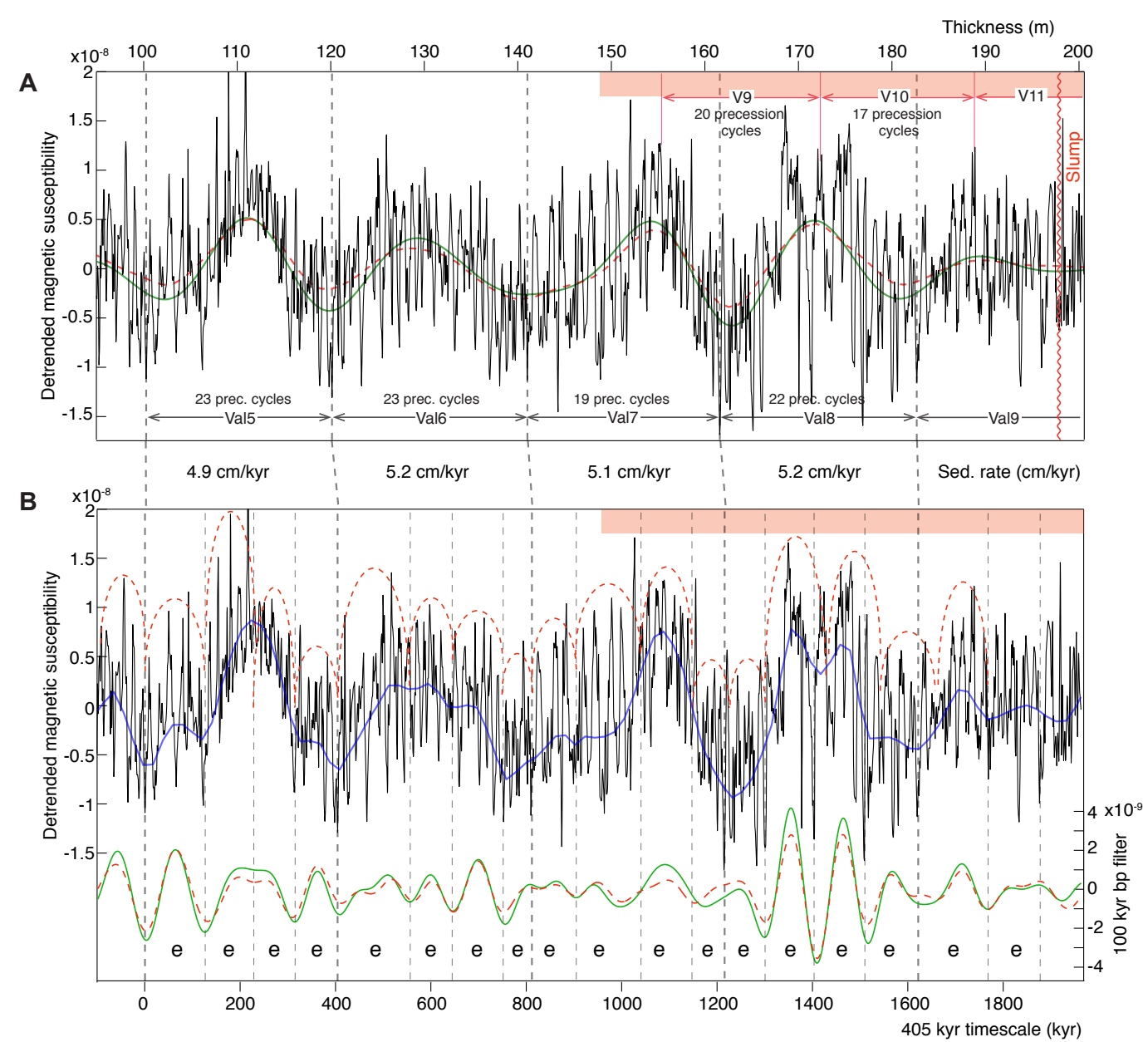

Figure 4: $405 \mathrm{kyr}$ orbital tuning of magnetic susceptibility (MS) variations of the Late Valanginian interval at Orpierre section (meters as in Charbonnier et al., 2013; the lowermost $\sim 3.25$-m-thick marly interval associated to the slump is measured and added here to show how the MS signal is disturbed). (A) Untuned detrended MS data by subtracting a $30 \%$ weighted average of the series. A $12 \%$ weighted average fit of the already detrended $(30 \%$ weighted average) series (solid line) and a gaussian bandpass filter $(0.05 \pm 0.03$ cycles $/ \mathrm{m}$, dashed line) are performed to highlight the interpreted $405 \mathrm{kyr}$ eccentricity cycles Val5 to Val9 p.p.. Number of precession cycles within each $405 \mathrm{kyr}$ cycle are also shown. V9, V10 and V11 are $405 \mathrm{kyr}$ eccentricity cycles equivalent to those interpreted by Martinez et al. (2013) from Reynier/Angles and Vergol/Morénas/La Charce composite sections (see Fig. 2). The orange shaded interval encompassing V9, V10 and V11, corresponds to that in which Martinez et al. (2013) have interpreted the couplets as having an obliquity origin. (B) $405 \mathrm{kyr}$ tuned MS. Weighted average smoothing (upper curve fit) and bandpass filtering $(0.009 \pm 0.004$ cycles/kyr, lower curve) are applied to the tuned MS data to show the short (100 kyr) eccentricity cycles (indicated by 'e'). Average sedimentation rates inferred from the $405 \mathrm{kyr}$ tuning are also shown. Note that because of the high variability in MS amplitudes at the scale of couplets, it is difficult in several cases to capture boundaries of the short eccentricity cycles neither from filtering nor from smoothing techniques. For example, the middle Val5 cycle contains two amalgamated 'e' cycles not detected by smoothing, but slightly by filtering. Therefore, a possible interpretation from visual inspection is also proposed by dashed arcs.

\subsection{Time series analysis of the Orpierre section}

Spectral analysis of the untuned data (Fig. 5A) shows three distinct areas of significant high-frequency peaks. A single peak is centered on the wavelength of $0.65 \mathrm{~m}$. Multiple peaks are concentrated around $1 \mathrm{~m}$, which are spread over the wavelength band 0.85 to $1.11 \mathrm{~m}$. Finally, a double peak is characterized by wavelengths of 1.37 and $1.47 \mathrm{~m}$. At lower frequencies, we note three significant peaks. One is centered on the wavelength of $2.81 \mathrm{~m}$. Another less significant peak has a wavelength of $5.55 \mathrm{~m}$. Finally, a highly significant strong peak is centred on $18.52 \mathrm{~m}$. This wavelength represents the Val5 to Val9 cycles. Calibrating the $18.52 \mathrm{~m}$ to the $405 \mathrm{kyr}$ eccentricity results in temporal periods (Fig. 5B) 
sharing some similarities with the astronomical periods (Fig. 5C). Particularly, the wavelength band 0.85 to $1.11 \mathrm{~m}$ is calibrated to a period band of 17 to $21.5 \mathrm{kyr}$ matching the precession band; the $5.55 \mathrm{~m}$ wavelength is calibrated to $116.7 \mathrm{kyr}$, close to the mean short eccentricity. This cyclicity is recorded throughout the section, and is stronger within the Val8 cycle (Fig. 4). The $0.65 \mathrm{~m}$ peak is tuned to $12.7 \mathrm{kyr}$, which may represent a shortened precession term or sub-Milankovitch variations or it could be also linked to temporally uncorrected sedimentation rate. The double peaks of 1.37 and $1.47 \mathrm{~m}$ are tuned to 26.3 and 28.6 kyr respectively. These periods would correspond to the obliquity terms. They were interpreted by Charbonnier et al. (2013) as corresponding to obliquity components (their figure 7). However, visual inspection of cycle counting in the tuned time series, aided by bandpass filtering (Fig. 6) indicates that the 1.37 and $1.47 \mathrm{~m}$ correspond to precession cycles, recorded by thicker couplets. As a result, the $405 \mathrm{kyr}$ tuning procedure fails in aligning these wavelengths to periods that would represent the $\mathrm{P} 1$ precession component (Fig. $5 \mathrm{C}$ ). This problem was also encountered in the Kimmeridgian marl-limestone alternations (e.g., Boulila et al., 2008b their figure $5 \mathrm{C}$ ), and the Triassic sequences (L. Hinnov, pers. comm.). The high variability in sedimentation rate at the scale of couplets precludes the alignment of temporal periods to astronomical periods (see Fig. 6B, lower curve). The $2.81 \mathrm{~m}$ peak is calibrated to $54.8 \mathrm{kyr}$ (Fig. 5). This period does not match any astronomical period. Visual inspection indicates that the $54.8 \mathrm{kyr}$ may correspond to obliquity cycles, bundling the precession cycles (Fig. 6B,D). This cyclicity occurs intermittently through the section (see black stars in Fig. 6B).

When the couplets are assumed as precession in origin (i.e., 20 kyr tuning, Fig. $7 A, B, C)$ such temporal calibration successfully captures the long-wavelength $(18.5 \mathrm{~m})$ with a period very close to the $405 \mathrm{kyr}$ eccentricity term. This exceptional result strengthens the hypothesis that the couplets are precession in origin and the supercouplets originate from the eccentricity terms. Also, tuning at the short eccentricity band (Fig. 7D,E,F) provides strong constraints on the origin of couplets, which are mainly calibrated to $20 \mathrm{kyr}$ and $24 \mathrm{kyr}$. We have also noted in the $20 \mathrm{kyr}$ tuning that the obliquity is recorded intermittently regrouping two precession cycles (see comments on Fig. 7C).

Results of evolutive harmonic analysis (EHA) in the depth domain (Fig. 2A), and by focusing on evolution of precession (couplets) cycles, highlight net oscillations in sedimentation rate along the whole section. Visual inspection indicates that the precession cycles are sometimes thicker and sometimes thinner, confirming previous interpretations from single spectra. In particular, sedimentation rate follows the interpreted $405 \mathrm{kyr}$ cycles from MS data (see Val5-Val7 in Fig. 2A). Sedimentation rate decreases within the decreasing parts of $\mathrm{MS}$ (increasing $\% \mathrm{CaCO}_{3}$ ), and increases within the increasing parts of $\mathrm{MS}$ (decreasing $\% \mathrm{CaCO}_{3}$ ). This result is potentially interpreted in terms of sea-level change (Section 3.2.2). EHA of Orpierre data is then compared to EHA of RA and VMC data (Section 2.3.1). EHA of the questionable interval (Fig. 8) shows evidence of precession modulated by the short eccentricity.

Additional evidence for amplitude modulation (AM) of the precession by the eccentricity is highlighted using hilbert transform of the filtered precession band together with bandpass and lowpass filtering (Fig. 9). Hilbert transform of the $405 \mathrm{kyr}$ tuned MS data (Fig. $9 \mathrm{E}, \mathrm{F})$ detects most of the short eccentricity cycles, detected by bandpass and lowpass filtering (Fig. 9B,D,G), and also by visual inspection of the cyclic MS variations (Fig. 4B). AM output (Fig. 9E) fails, however, in the detection of the $405 \mathrm{kyr}$ eccentricity component. This negative result is compensated by the $20 \mathrm{kyr}$ tuning (discussed above) that strongly captures the 405 kyr cyclicity (Fig. 7B).

In summary, the most prominent cyclicities are the precession modulated by the 100 and 405 kyr eccentricity (Figs. 4 and 5). The obliquity is recorded by intermittently regrouping two precession cycles. 

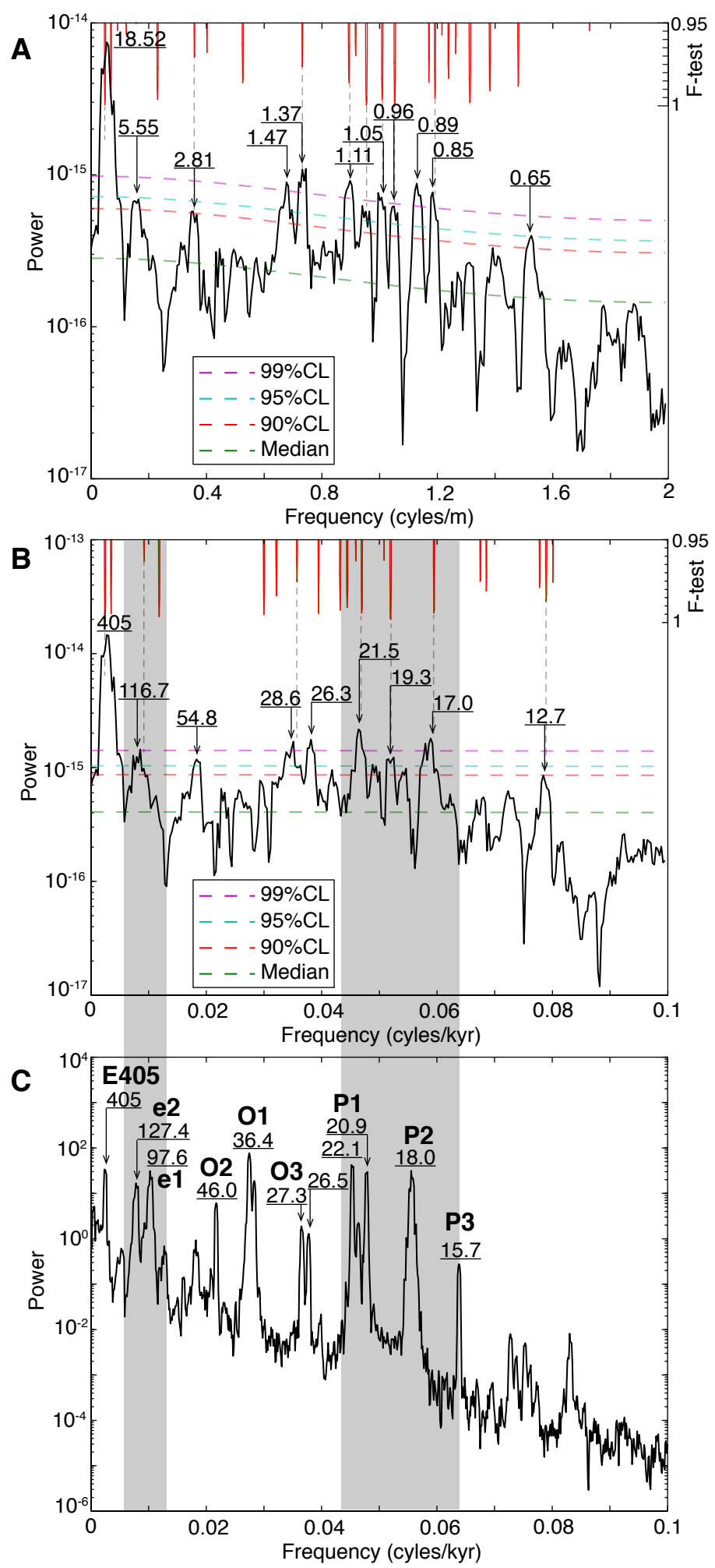

Figure 5: $2 \pi-M T M$ power spectra of magnetic susceptibility (MS) variations in the Orpierre section (SE France). (A) Spectrum of the untuned interval from 94.94 to $200.53 \mathrm{~m}$ (curve in Fig. 4A). Thomson's harmonic F-test (Thomson, 1982) is used in parallel with the robust red noise (Mann and Lees, 1996) in order to interpret significant spectral periods that could be related to orbital frequencies. (B) Spectrum of the 405 kyr tuned MS (curve in Fig. 4B) with the same statistical tests as in 'A'. (C) Spectrum of the La2004 astronomical variations (Laskar et al., 2004) in ETP format (Eccentricity, Tilt, Precession, e.g., Imbrie et al., 1984, pp. 296-297) for the interval from 140.2 to $133.9 \mathrm{Ma}$, corresponding to the Valanginan stage (Ogg et al., 2008). Shaded areas indicate precession and short (100 kyr) eccentricity cycle bands. Symbols: P1, P2 and P3 for precession; O1, O2 and O3 for obliquity; e1 and e2 for short (100 kyr) eccentricity; E405 for 405 kyr eccentricity. Comparison between frequencies in the sedimentary record $(B)$ and astronomy $(C)$ is discussed in Section 2.2. 

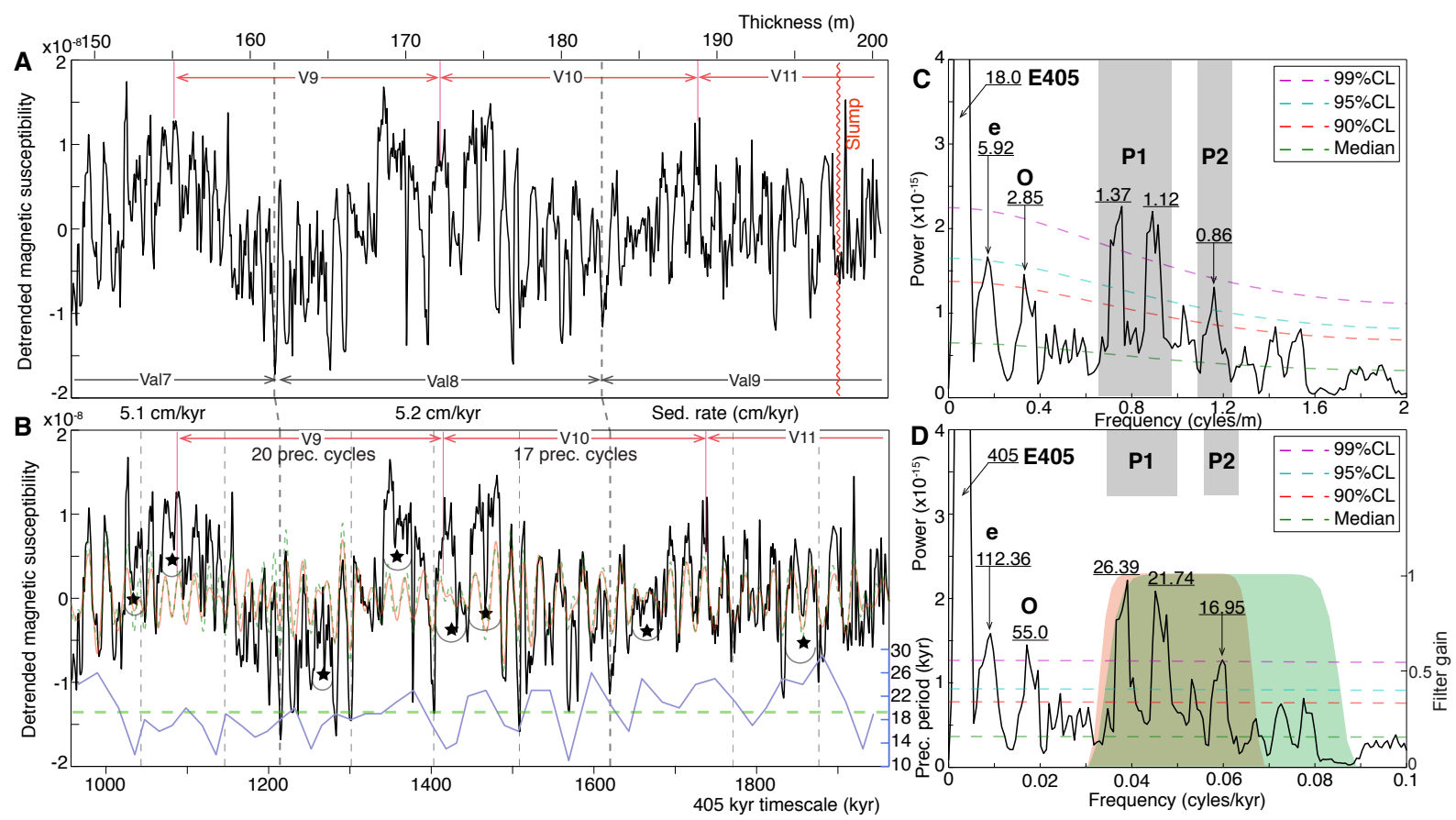

Figure 6: Time-series analysis of the orange-shaded interval in Fig. 4, in which there were controversial interpretations (Charbonnier et al., 2013; Martinez et al., 2013) concerning precession vs obliquity driven couplets. (A) Untuned detrended magnetic susceptibility (MS), from Fig. 4A. (B) Tuned MS, from Fig. 4B. Bandpass filtering is applied to recover the precession cycle band. Examples of obliquity cycles are indicated by black stars, bundling the precession cycles (grey arcs). Note that the obliquity signal occurs intermittently, and the couplets were driven by the precession (see text for discussion). Calculated precession periods are also shown with a mean of $19.19 \mathrm{kyr}$ (dashed line). (C) $2 \pi-M T M$ spectrum of ' $A$ '. Values of wavelengths are in meter. Shaded areas represent $\mathrm{P} 1$ and $\mathrm{P} 2$ precession terms, 'O' for obliquity, ' $\mathrm{e}$ ' for short eccentricity, and 'E405' for 405 kyr eccentricity. The strongest peak at $18 \mathrm{~m}$ is truncated to highlight the high-frequency portion of the spectrum (its total power is $9 \times 10^{-15}$ ). (D) $2 \pi-M T M$ spectrum of ' $B$ '. Values of periods are in kyr. Two passbands, indicated by the shaded areas, are used to filter the precession cycle band in ' $\mathrm{B}$ '. We used the Taner filter (Taner, 2000). Note that the $26.39 \mathrm{kyr}$ peak is a precession period, which is not aligned by the $405 \mathrm{kyr}$ tuning procedure (see curve of "precession periods" in 'B').

\subsection{Cyclostratigraphic correlation}

\subsubsection{Evidence for hiatuses from the $405 \mathrm{kyr}$ cycle correlation}

The three Late Valanginian sections (Orpierre, RA and VMC) are easily correlatable owing to biostratigraphy (Martinez et al., 2013; Charbonier et al., 2013) and several carbonate-rich intervals that serve as lithostratigraphic markers (F.V., F.P., F.Pe. and F.N., see Fig. 2). They correspond to grouped carbonate-rich beds, recognized throughout the Vocontian Basin, forming striking features in the outcrops (Fig. 10). These lithostratigraphic markers coincide with extrema in the $405 \mathrm{kyr}$ eccentricity cycles (Section 2.2). We carried out a detailed correlation at the $405 \mathrm{kyr}$ eccentricity cycle band. The $405 \mathrm{kyr}$ eccentricity cycles were identified as Val5 to Val9 from carbonate maxima/MS minima (Charbonnier et al., 2013), and as V6 to V11 from clay maxima/GRS maxima (Martinez et al., 2013). The shaded interval, encompassing $\mathrm{V} 9, \mathrm{~V} 10$ and $\mathrm{V} 11$ at RA and VMC sections, corresponds to the interval in which the couplets were interpreted as obliquity in origin (Martinez et al., 2013). The V9 and V10 cycles at Orpierre are well constrained (Fig. 2). However, the V11 cycle at Orpierre occurs within a $5 \mathrm{~m}$ thick slump and thus was not considered (Fig. 2).

The first remarkable feature in the MS and GRS records is the strong expression of the 405 kyr eccentricity cycles, which are prominent in MS throughout the studied interval (Fig. 2A) and less in GRS; only the $405 \mathrm{kyr}$ Val7 cycle is strongly recorded in GRS, especially 
in RA section (Figs. 2 and 3). This differential expression may be due to several factors: the sampling resolution ( $7 \mathrm{~cm}$ for MS vs $20 \mathrm{~cm}$ for GRS, Fig. S1), the sensitivity of MS and GRS devices, and/or the occurrence of hiatuses at RA and VMC sections (see below).

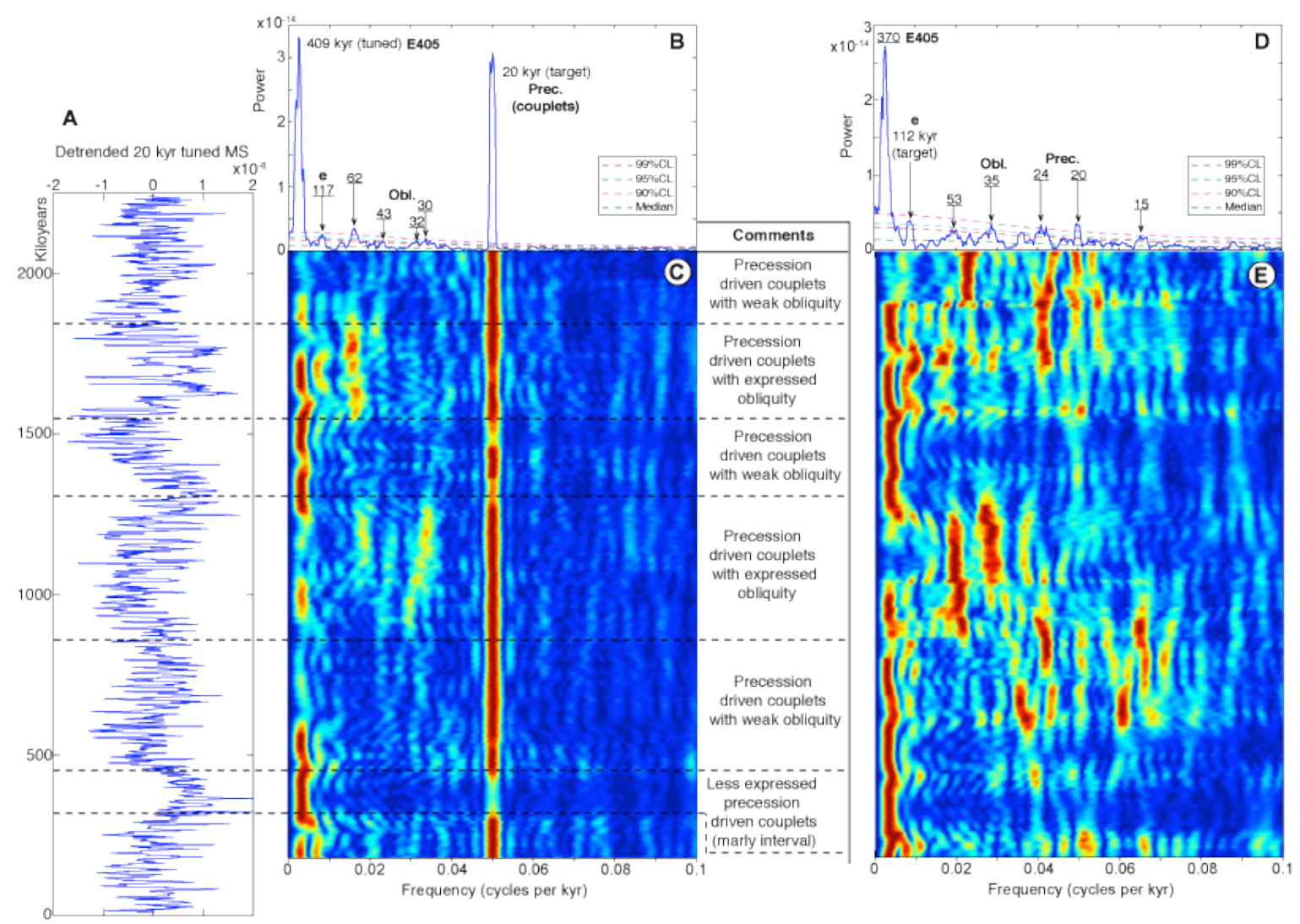

Figure 7: Results of tuning of MS data (Orpierre section, Fig. 2A) at the precession and short eccentricity bands. (A) Tuned MS time series at the precession (couplet) cycle band (we used a period of $20 \mathrm{kyr}$, which is approximately the mean of P1 and P2 in La2004 astronomical model, see Fig. 5C). (B) and (C) are respectively the spectrum and the amplitude spectrogram of the $20 \mathrm{kyr}$ tuned MS. This tuning resulted in a period of $409 \mathrm{kyr}$ for the long $(18.52 \mathrm{~m})$ wavelength, which is close to the long (405 kyr) eccentricity term. (D) and (E) are respectively the spectrum and the amplitude spectrogram of the short eccentricity tuned MS (we used a period of $112 \mathrm{kyr}$, which is approximately the mean of e1 and e2 in La2004 astronomical model, see Fig. 5C). This tuning resulted in a period of $370 \mathrm{kyr}$ for the long ( $405 \mathrm{kyr})$ eccentricity term, but successfully calibrated a significant, well-defined peak depicting the couplets to $20 \mathrm{kyr}$. Another significant peak of $24 \mathrm{kyr}$ represents also the couplets.

Note that the obliquity is present, intermittently well expressed (see "comments" on amplitude spectrogram in "C") but the couplets were always driven by the precession.

Vergol-Morénas section has very thick Val5 cycle compared to Orpierre and Reynier (Fig. 3) because it is located nearer the margin of the basin (Fig. 1), a location that was more influenced by clay input. This is supported by the occurrence of clay-rich interval within Val5 cycle, which is very similar in the two close Orpierre and Reynier locations (Fig. 3), but notably much expanded in Vergol-Morénas. Val6 cycle has the same thickness in Orpierre and RA sections, but slightly thicker in RMC section. Val7 cycle is thicker in Orpierre than in Angles and much thinner in La Charce. Here, sedimentation rate does not vary according to proximal-distal environments in the basin and its surrounding margins (Sections 2.3.1 and 3.1). Val8 cycle is very much thicker in Orpierre than in RA and VMC, about twice thicker in VMC. This is due to the hiatuses (Fig. 3 and Section 2.3.1)

We counted the number of precession cycles within each $405 \mathrm{kyr}$ cycles in the questionable interval, but following the terminology used by Martinez et al. (2013) (i.e., V9V11). The V9 cycle at Orpierre contains 20 couplets compared to only 10 at RA and 12 at 
VMC. The V10 cycle includes 17 couplets at Orpierre versus 9 at RA and 10 at VMC. Moreover, V9 and V10 cycles are well expressed at Orpierre, but less at RA and VMC (Fig. 2B,C). Interestingly, short eccentricity cycles within V9 and V10 are well expressed at Orpierre (see Section 2.3.1), while a single obliquity driven couplet within the $405 \mathrm{kyr}$ eccentricity cycles was previously suggested (Martinez et al., 2013).

The V9 and V10 cycles are thinner at RA, and especially at VMC compared to those at Orpierre. The occurrence of barite nodules within V9-V10 transition at RA (Angles section, Martinez et al., 2013) may be an indicator of a decrease in sedimentation rate or hiatuses (e.g., Torres et al., 1996), leading to reduced number of couplets. However, the stratigraphic position of the barite nodules as indicated by Martinez et al. (2013) (their figures 2 and 5) does not correspond to any decrease in sedimentation rate. On the contrary, there is an abrupt increase in sedimentation rate within V9, immediately below the barite nodules (Fig. 2B), hence in favor of the hiatus hypothesis.

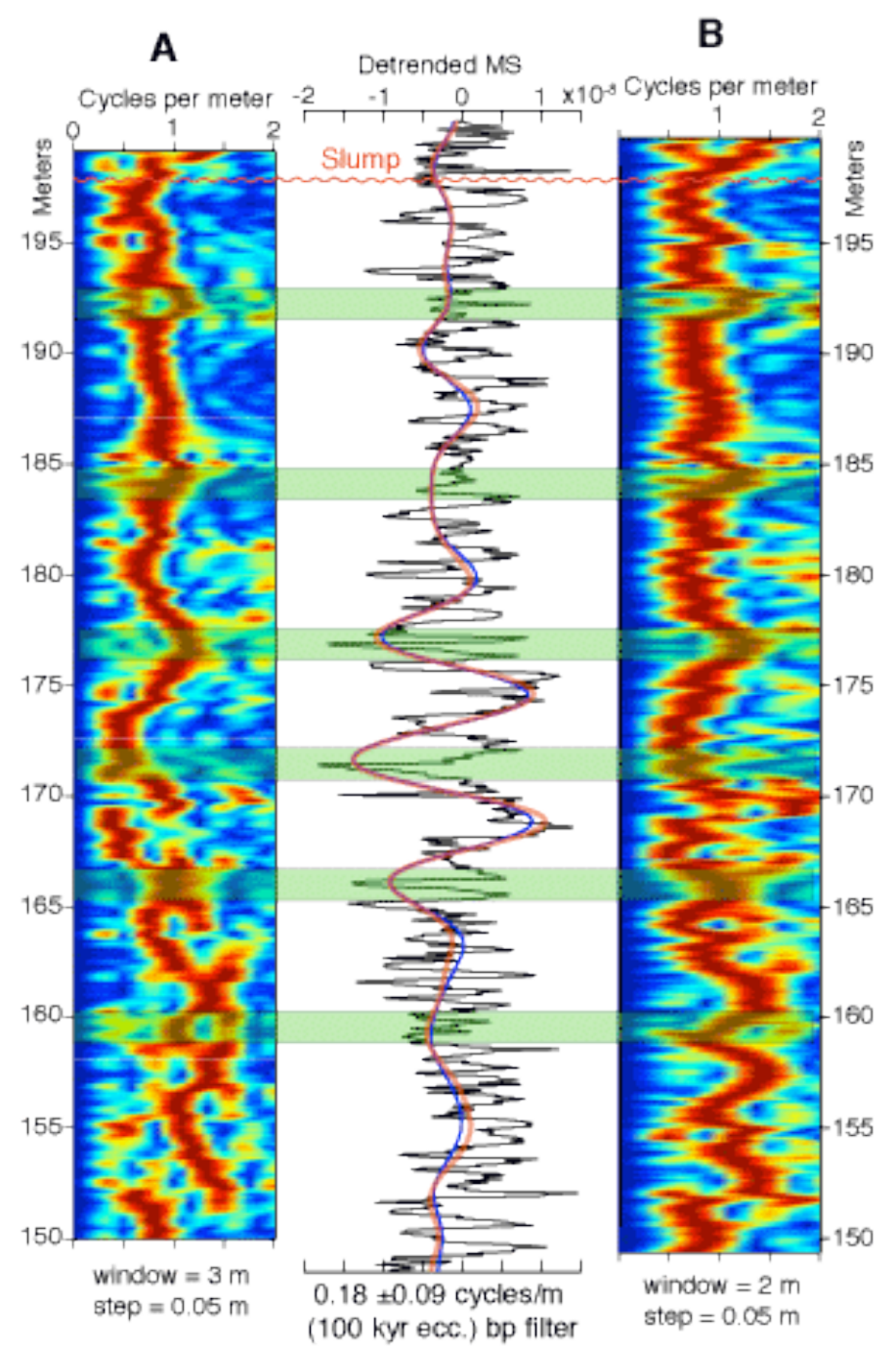

Figure 8: Evolutive harmonic analysis (EHA) of magnetic susceptibility (MS) data at Orpierre section, a focus on the questionable interval (Fig. 6A) showing the strong expression of the precession modulated by the $100 \mathrm{kyr}$ eccentricity. A $100 \mathrm{kyr}$ bandpass filter is also applied to the raw data. (A) and (B) EHA using two different windows. 
Evolutive harmonic analysis of RA spectacularly detects the abrupt shift towards higher sedimentation rates, precisely at the position of the hiatus, which is detected and quantified using high-resolution cyclostratigraphic correlation (Fig. 3, Section 2.3.2). This change is also visible in VMC. The hiatus corresponds to a "condensation" in Orpierre (Section 2.3.2).

Hiatuses would have significantly reduced the number of couplets within the $405 \mathrm{kyr}$ cycles at RA and VMC according to our correlation (Fig. 2 and Figs. S2 to S4). Strong evidence of a higher number of couplets within the $405 \mathrm{kyr}$ cycles comes from the more continuous section at Orpierre (Fig. 2A). The shortened V11 cycle at Orpierre occurs within a slump. This may concur with a possible hiatus within this cycle, reducing the number of couplets in all the three sections in the basin.

All these remarks (see also Section 2.3.2) point to precession driven couplets, and potential occurrence of hiatuses at RA and VMC that misled the interpretation of the couplets as controlled by the obliquity (Martinez et al., 2013). Below, we carried out a high-resolution cyclostratigraphic correlation, at the scale of precession cycles, in order to detect and quantify the aforementioned hiatuses.
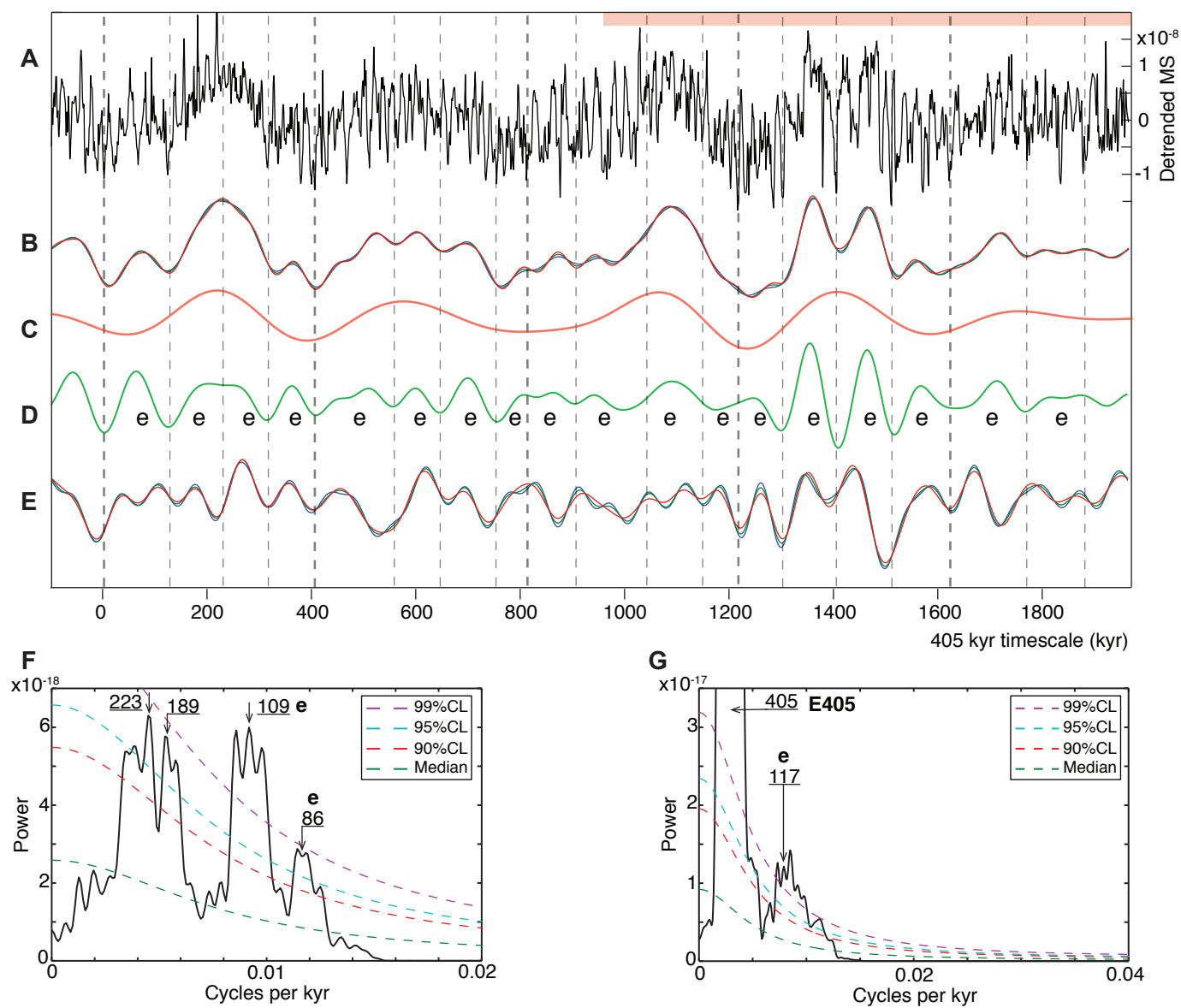

Figure 9: Filtering and amplitude modulation ( $A M)$ of the $M S$ time series in the Orpierre section. (A) The detrended tuned MS time series (as in Fig. 4B). (B) Lowpass filtering applied to 'A' to recover both short (100 kyr) and $405 \mathrm{kyr}$ eccentricity cycles. (C) Bandpass filtering applied to ' $A$ ' to recover $405 \mathrm{kyr}$ eccentricity cycles. (D) Bandpass filtering applied to ' $A$ ' to recover short eccentricity cycles. (E) $A M$ of the precession cycle band. (F) $2 \pi-$ MTM spectrum of ' $E$ '. (G) $2 \pi-M T M$ spectrum of ' $B$ ', the strongest 405 kyr peak is truncated (its total power is $\left.15 \times 10^{-17}\right)$. Note that the short eccentricity is detected either in the raw tuned data $(G)$ or in the $A M$ of the precession cycle band $(F)$, while the $405 \mathrm{kyr}$ eccentricity is not detected in AM time series (F). It is, however, detected in the precession tuned time series (see Figs. 7A,B,C) Symbols "e" and "E405" indicate respectively the short eccentricity, and the 405 kyr eccentricity cycles (see aslo Fig. 5). 


\subsubsection{High-resolution (precession) cyclostratigraphic correlation}

The high-resolution cyclostratigraphic correlation (Fig. 3) indicates that the RA and VMC sections have almost the same number of precession driven couplets. In only one stratigraphic level, we noted two differential precession cycles between these sections, which could be linked to minor hiatuses, problem of preservation/expression and/or due to other sedimentary factors (see Fig. S2-S4). However, correlation with the more complete Orpierre interval shows five missing precession cycles (i.e., a duration of $100 \mathrm{kyr}$ ) within the same aforementioned stratigraphic position. The missing cycles occurred within the upper part of Val6 cycle, at a remarkably shift in amplitude of physical GRS proxy, especially in RA. They coincide with the junction level between Reynier and Angles. The change in amplitude of GRS is less marked in VMC, in which the junction level between Vergol-Morénas and La Charce is slightly below the shift. Therefore, we cannot rigorously consider the five missing cycles as hiatus, linked to a change in amplitude of physical proxy, but they likely result in a problem when generating the composite signals of RA and VMC.

Two significant hiatuses could be noted in RA and VMC sections within Val8 cycle, in the questionable interval. The $\sim 80 \mathrm{kyr}$ hiatus took place at an abrupt increase in sedimentation rate, which is very visible in RA (Angles section, Fig. 2B). The more pronounced increase in sedimentation rate in Angles compared to La Charce and Orpierre (Fig. 2) could be explained by the fact that Angles is more proximal to the margins (Fig. 1), a location more sensitive to change in sedimentation rate. Nevertheless, the $\sim 80 \mathrm{kyr}$ hiatus (Fig. 3) corresponds to a "condensed" interval in Orpierre. This result is in contradiction with one depositional model, discussed in Section 3.2.2: If sea level is high at the carbonate-rich interval, that corresponds to the "condensed" interval in the more distal Orpierre section, then sedimentation should be more continuous at the more proximal Angles (RA) section. When sea level is high, proximal environments have more positive accommodation space in favor for sediment accumulation. However, this model is again not respected because the hiatus occurred also in the La Charce (VMC) section, which is distal and nearer to Orpierre. Irregular bathymetry in the Vocontian Basin may preclude the application of variations in sedimentation rate in terms of proximal-distal setting in the basin and its margins (Section 3.1). Taken alone, the more complete Orpierre section records oscillations in sedimentation rate, in tune with the $405 \mathrm{kyr}$ orbitally driven sea level change (Section 3.2). The $\sim 160 \mathrm{kyr}$ hiatus occurred in the middle part of Val8 cycle, where sedimentation rate is significantly high in the three sections. This hiatus could alternatively be placed at the stratigraphic position of the barite nodules, recognized in Angles section (Fig. 3).

\section{Discussion}

\subsection{Precession versus obliquity control of the Late Valanginian marl-limestone couplets}

In the questionable interval (obliquity vs precession forcing hypothesis), the cyclostratigraphic correlation shows a reduced number of couplets within the $405 \mathrm{kyr}$ eccentricity cycles, especially in the RA and VMC sections. We have counted 17 to 20 couplets at Orpierre versus only 9 to 12 couplets at RA and VMC. This has led previous study to conclude that the ratio 1/10 (i.e., 10 couplets within each $405 \mathrm{kyr}$ cycle) at RA and VMC as indicating obliquity forcing of the couplets (Martinez et al., 2013). The Orpierre section shows no abrupt shift in sedimentation rate at the scale of the $405 \mathrm{kyr}$ cycles. In contrast, we note impressive oscillations in sedimentation rate detected through the change in wavelength of the precession driven couplets (Fig. 2A). We suggest that hiatuses at the scale of couplets had shortened the record of $405 \mathrm{kyr}$ cycles, especially in RA and VMC. Interestingly, high-resolution cyclostratigraphic correlation (Section 2.3.2) allowed the 
detection and quantification of the hiatuses, that occur mainly within the questionable interval. Potential hiatuses have also been detected in the Lower Kimmeridgian, using a cyclostratigraphic correlation, while no sedimentary indicators are seen in the field because of the relatively homogeneous facies (Boulila et al., 2008a). Another evidence for precession forcing from the Orpierre section, which again disagrees with the hypothesis of obliquity driven couplets (Martinez et al., 2013), is the documentation of the short eccentricity modulations. EHA highlights the precession band with a prominent modulation by the short eccentricity, especially within the questionable interval (Fig. 8).

In addition, we suggest possible local responses in the basin to clay input and/or carbonate production causing different numbers of couplets within the $405 \mathrm{kyr}$ cycles. This does not mean that the forcing is not global, but differential responses from different parts of the basin, due to variable bathymetry for example, are likely (see below). This would lead to developed or reduced couplets, and even to "missed beats" (i.e., a couplet reduced to a limestone bed or to a marly level because of the more or less sensitivity of the paleoenvironments to insolation/climate forcing). As an illustration, in the marl-limestone alternations of Lower Kimmeridgian sections in the Vocontian Basin, we have noted a striking change in the thickness and distribution of couplets. For instance, simple marl-limestone couplets having a precession origin (e.g., La Méouge section, Boulila et al., 2008b) are correlated to complex "couplets" of multiple marl-limestone alternations having a subMilankovitch origin (e.g., La Cluse section). Such strong variability in couplet expression is linked to the presence of irregular paleobathymetry in the Vocontian Basin (e.g., Pederneiras, 1995; de Rafélis et al., 1997; Moussine-Pouchkine et al., 1998; Beltran, 2007), resulting from tilted blocks of the Jurassic extensional tectonic phase (e.g., Dardeau et al., 1988), and had also influence on the early Cretaceous sedimentation (e.g., de Graciansky and Lemoine, 1988). Variable ocean paleodepths would differentially influence clay/carbonate deposition via sea level, which would in turn impact several processes (sedimentation rate, detrital input, carbonate productivity, carbonate import from shallow settings, ...).

In summary, the couplets always match the precession cycle band. The obliquity appears intermittently regrouping two precession cycles (two couplets, Figs. 6B and 7C). This strongly opposes to the hypothesis of unique obliquity forcing of the couplets along the questionable interval (Martinez et al., 2013). For instance, we noted within Val8 cycle the expression of both the precession (couplets) and the obliquity (Fig. 7C). The notably high sedimentation rate within Val8 cycle, and possible hiatuses and/or "missed beats" in RA and VMC sections may led to the hypothesis of obliquity forcing of the couplets.

\subsection{Astroclimatically driven sea-level change during the Late Valanginian}

\subsubsection{5 kyr eccentricity controlled fourth-order sea-level sequences}

Astronomical modeling and sedimentary records indicate that, because of its strongest amplitude, the $405 \mathrm{kyr}$ cycle played an important role in climato-eustatically driven Cenozoic and Mesozoic sequences (see Boulila et al., 2011 and references therein). The net variations in sedimentation rate, in tune with the exceptionally recorded $405 \mathrm{kyr}$ cycles in Orpierre (Fig. 2A, see Section 3.2.2) that match fourth-order eustatic sequences (Boulila et al., 2011), are also in favor of climato-eustatically induced supercouplets modulating the couplets (precession). There is a broad consensus that insolation forcing from the $405 \mathrm{kyr}$ eccentricity cycle is well documented in several paleoclimatic proxies (e.g., Pälike et al., 2006; Westerhold et al., 2007; Hilgen et al., 2010, among many others).

The 405 kyr eccentricity sea-level related cyclicity in the studied Valanginian sections (Section 3.2.2) modulates the short (100 kyr) eccentricity and the precession (couplets) cycles. This result provides a compelling evidence for the hierarchical, astroclimatic control of sea-level change. 
In the sequence stratigraphic terminology, the $405 \mathrm{kyr}$ eccentricity related sea-level cycles match the fourth-order depositional sequences, the $100 \mathrm{kyr}$ eccentricity the fifth-order sequences, and the fundamental precession (dominated couplets) the sixth-order sequences (Boulila et al., 2011). In the studied sections, the $405 \mathrm{kyr}$ eccentricity cycle extrema are reflected by the pronounced lithostratigraphic markers/intervals (Section 3.2.2). These intervals are striking in the outcrops, and are correlatable at the scale of the Vocontian Basin (Cotillon et al., 1980). This is a good argument for the high amplitude of the $405 \mathrm{kyr}$ orbital cycle, which is in accord with the theoretically predicted $405 \mathrm{kyr}$ leading term in the eccentricity components (e.g., Laskar et al., 2004).

It has also been demonstrated that the third-order sequences in greenhouse periods match the long-period (g4-g3) eccentricity cycle (its mean periodicity in the Cenozoic is 2.4 Myr, Boulila et al., 2011). However, the studied interval is too short to detect this long wavelength. One possible extremum in the g4-g3 related variation is with more important amplitude (Fig. 2A, see also figure 6 of Charbonnier et al., 2013). This extremum matches the "Faisceau à Peregrinus" (F.Pe.) lithostratigraphic marker, which may have more importance in terms of amplitude transferred orbital signal.

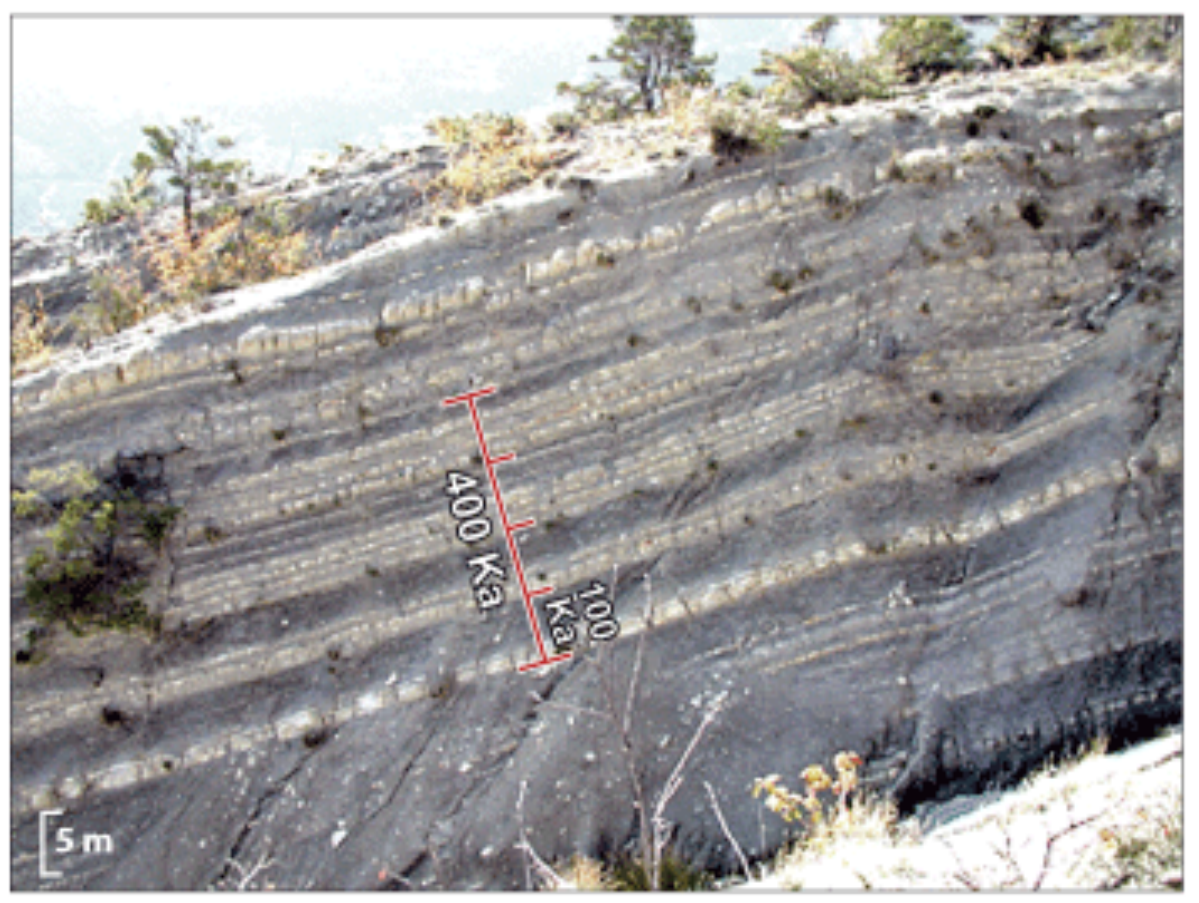

Figure 10: A filed photograph in the La Charce section (Late Valanginian, SE France) showing a striking bundling of couplets (precession) by the short (100 kyr) and 405 kyr eccentricity cycles (from Deconinck, 2006).

\subsubsection{Phase relationship between SL change and astronomically controlled climate}

Previous sedimentological studies suggested that sea level controlled the deposition of couplets and supercouplets during the Valanginian (Gréselle and Pittet, 2010).

The detection of variations in sedimentation rate in tune with the $405 \mathrm{kyr}$ eccentricity cycles (Val5-Val6-Val7) from the more complete Orpierre section is potentially used to interpret sea-level change. Sedimentation rate slows down in the decreasing part of MS data (i.e., increasing $\% \mathrm{CaCO}_{3}$ ) to reach the lowest values at the carbonate-rich intervals (Fig. $2 \mathrm{~A}$ ). Interestingly, most of the well known lithostratigraphic markers fall at these lower sedimentation rates associated with carbonate-rich intervals. The lithostratigraphic markers are a commun feature for the three sections, because they were caused by orbitally forced 
sea-level variations, which were deposited everywhere in the basin (Section 3.2.1). Accordingly, we suggest that these carbonate-rich intervals were formed under highstand conditions, whereas the clay-rich intervals under lowstand conditions. This hypothesis concurs with the proposed sequence boundaries and lowstand system tracts at the clay-rich intervals, using an extensive sequence stratigraphic study of Berriasian through Barremian sequences from both the tethyan and the boreal domains (Hoedemaeker and Herngreen, 2003).

This depositional model supports the principles set forth for pelagic carbonate sequence stratigraphy in the Exxon sequence stratigraphic model (Handford and Loucks, 1993): maxima of orbitally forced insolation are associated with high sea-level, weaker continental erosion, and reduced detrital input. Minima of insolation contribute to low sealevel, increasing erosion of detrital materials and their transport to the basin. The model considers that the carbonate production was in situ formed in the pelagic realm.

However, such interpretation is opposite to the model previously applied for these sections, which assumes that the limestones were mainly formed by cyclic carbonate mud export from the adjacent shallow platforms (Gréselle and Pittet, 2010): when sea level is high, carbonate produced within the platform remains on the platform, thus we form the marly intervals. In contrast, when sea level is low, the carbonate factory moves offshore and delivers more carbonate to the basin, thus we form the limestone beds. This model should equally be considered untill a high-resolution oxygen stable isotopes and calcareous nannoplankton analysis can discriminate one of these two models (e.g., Boulila et al., 2010).

\section{Conclusions}

Controversial interpretations of Late Valanginian cyclostratigraphy (Vocontian Basin, SE France) lead to two different hypotheses: precession versus obliquity control of the marllimestone couplets. High-resolution cyclostratigraphic correlation among all studied sections, together with time-series analysis applied to the most complete interval possessing the best constrained paleoclimatic record in the Orpierre section, shows evidence of precessiondriven couplets modulated by the short and $405 \mathrm{kyr}$ eccentricity. Such orbital modulations of the precessional driven couplets further support previously proposed hierarchical link of climato-eustatically forced sequences, with the prominent $405 \mathrm{kyr}$ cycles matching the fourthorder ones. More striking is the strong expression of long-period orbital cyclicities, controlling variations in sedimentation rate, which further supports their strong impact on climate and sea-level variations. The long-time known, pronounced lithostratigraphic markers in the basin (basin-scale correlative intervals) match the 405 kyr eccentricity cycle extrema.

\section{Acknowledgments}

S. Boulila and B. Galbrun are grateful for support from the ISTEP laboratory and CNRS-INSU SYSTER grant2015. S. Boulila thanks very much Jacques Laskar (Paris Observatory, IMCCE Laboratory) for very helpful discussion about the astronomical aspects. We are grateful for the thoughtful reviews provided by the reviewers and the Editor that considerably improved the paper.

\section{References}

Beltran C., 2007. Variations des paramètres de l'environnement océanique au cours de la sédimentation d'un doublet marne-calcaire: approches géochimique, minéralogique et micropaléontologique. Doctoral Dissertation, University P. et M. Curie, Paris, France, 247 pp.

Boulila, S., de Rafélis, M., Hinnov, L.A., Gardin, S., Galbrun, B., Collin, P.-Y., 2010. Orbitally forced climate and sea-level changes in the Paleoceanic Tethyan domain (marl-limestone alternations, Lower Kimmeridgian, SE France). Palaeogeogr. Palaeoclim. Palaeoecol. 292, 57-70.

Boulila, S., Galbrun, B., Hinnov, L.A., Collin, P.Y., 2008a. Orbital calibration of the Early Kimmeridgian (southeastern France): implications for geochronology and sequence stratigraphy. Terra Nova 20, 455462.

Boulila, S., Galbrun, B., Hinnov, L.A., Collin, P.Y., 2008b. High-resolution cyclostratigraphic analysis from magnetic susceptibility in an Upper Kimmeridgian (Upper Jurassic) marl-limestone succession (La Méouge, Vocontian Basin, France). Sed. Geol. 203, 54-63. 
Boulila S., Galbrun B., Miller K.G., Pekar S.F., Browning J.V., Laskar J., Wright J.D. 2011. On the origin of Cenozoic and Mesozoic "third-order" eustatic sequences. Earth-Science Reviews 109, 94-112.

Charbonnier, G., Boulila, S., Gardin, S., Duchamp-Alphonse, S., Adatte, T., Spangenberg, J.E., Föllmi, K.B., Colin, C., Galbrun, B., 2013. Astronomical calibration of the Valanginian "Weissert" episode: the Orpierre marllimestone succession (Vocontian Basin, southeastern France). Cret. Res. 45, 25-42.

Cotillon, P., Ferry, S., Gaillard, C., Jautée, E., Latreille, G., Rio, M., 1980. Fluctuation des paramètres du milieu marin dans le domaine vocontien (France Sud-est) au Crétacé inférieur: mise en évidence par l'étude des formations marno-calcaires alternantes. Bulletin de la Société Géologique de France 7, t.XXII, 735-744.

Dardeau, G., Atrops, F., Fortwengler, D., de Graciansky, P.C., Marchand, D., 1988. Jeu de blocs et tectonique distensive au Callovien et à l'Oxfordien dans le bassin du Sud-Est de la France. Bull. Soci Géol. France 8 (IV, 5), 771-777.

Deconinck, J-F., 2006. Paléoclimats: l'enregistrement des variations climatiques. Société Géologique de France, Vuibert, $198 \mathrm{p}$.

de Graciansky, P.C., Lemoine, M., 1988. Early Cretaceous extensional tectonics in the southern French Alps: A consequence of North-Atlantic rifting during Tethyan spreading. Bull. Soci Géol. France 8 (IV, 5), 733-737.

de Rafélis, M., Robin, C., Renard, M., 1997. Les alternances marne-calcaire du Kimméridgien du Bassin du SudEst (France): Stratigraphie haute résolution et cycles de Milankovitch. $6^{\text {ème }}$ congrès Français de sedimentologie, Montpellier (France). Publications ASF, 27, p. 83.

Erba, E., Bartolini, A.C., Larson, R.L., 2004. Valanginian Weissert oceanic anoxic event. Geology 32, 149-152.

Ghil, M., Allen, M.R., Dettinger, M.D., Ide, K., Kondrashov, D., Mann, M.E., Robertson, A.W., Saunders, A., Tian, Y., Varadi, F., Yiou, P., 2002. Advanced spectral methods for climatic time series. Reviews of Geophysics 40, 1-41.

Giraud, F., Beaufort, L., Cotillon, P., 1995. Periodicities of carbonate cycles in the Valanginian of the Vocontian Trough: a strong obliquity control. In: House, M.R., Gale, A.S. (Eds.), Orbital Forcing Time Scales and Cyclostratigraphy. Geological Society Special Publication 85, 143-164 (London).

Gréselle, B., Pittet, B., 2010. Sea-level reconstructions from the Peri-vocontian Zone (South-east France) point to Valanginian glacio-eustasy. Sedimentology $57,1640-1684$.

Handford, C.R., Loucks, R.G., 1993. Carbonate depositional sequences and systems tracts responses of carbonate platforms to relative sea-level change. In: Loucks, R.G., Sarg, J.F. (Eds.), Carbonate Sequence Stratigraphy: Recent Advances and Applications: AAPG Memoir, 57, pp. 3-41.

Hilgen, F.J., Kuiper, K.F., Lourens, L.J., 2010. Evaluation of the astronomical time scale for the Paleocene and earliest Eocene. Earth Planet. Sci. Lett. 300(1-2), 139-151.

Hoedemaeker, P.J., Herngreen, G.F.W, 2003. Correlation of Tethyan and Boreal Berriasian - Barremian strata with emphasis on strata in the subsurface of the Netherlands. Cretaceous Research 24, 253-275.

Huang, C., Hinnov, L.A., Fischer, A.G., Grippo, A., and Herbert, T., 2010. Astronomical tuning of the Aptian Stage from Italian reference sections. Geology 38, 899-902.

Huang, Z., Ogg, J.G., Gradstein, F.M., 1993. a quantitative study of Lower Cretaceous cyclic sequences from the Atlantic Ocean and the Vocontian Basin (SE France). Paleoceanography 8, 275-291.

Imbrie, J., Hays, J.D., Martinson, D.G., McIntyre, A., Mix, A.C., Morely, J.J., Pisias, N. G., Prell, W.L., Shackleton, N.G., 1984. The orbital theory of Pleistocene climate: support from a revised chronology of the marine $\delta 180$ record. In: Berger, A.L., Imbrie, J., Hays, J.D., Kukla, G., Saltzman, B. (Eds.), Milankovitch and climate, part 1. D. Reidel Publishing Co., Dordrecht, pp. 269-305.

Laskar, J., Robutel, P., Joutel, F., Gastineau, M., Correia, A., Levrard, B., 2004. A long-term numerical solution for the insolation quantities of the Earth. Astron. Astrophys. 428, 261-285, doi:10.1051/0004-6361:20041335.

Mann, M.E., and Lees, J.M, 1996. Robust estimation of background noise and signal detection in climatic time series. Climatic Change 33, 409-445.

Martinez, M., 2013. Calibration astronomique du Valanginian et de l'Hauterivien (Crétacé inférieur): implications paléoclimatiques et paléocéanographiques. PhD thesis, Univ. de Bougogne, Dijon, $210 \mathrm{p}$.

Martinez, M., Deconinck, J.-F., Pellenard, P., Reboulet, S., Riquier, L., 2013. Astrochronology of the Valanginian Stage from reference sections (Vocontian Basin, France) and palaeoenvironmental implications for the Weissert Event. Palaeogeogr. Palaeoclimatol. Palaeoecol. 376, 91-102.

McArthur, J.M., Janssen, N.M.M., Reboulet, S., Leng, M.J., Thirlwall, M.F., van de Schootbrugge, B., 2007. Palaeotemperatures, polar ice-volume, and isotope stratigraphy $\left(\mathrm{Mg} / \mathrm{Ca}, \delta^{18} \mathrm{O}, \delta^{13} \mathrm{C},{ }^{87} \mathrm{Sr} /{ }^{86} \mathrm{Sr}\right)$ : the Early Cretaceous (Berriasian, Valanginian, Hauterivian). Palaeogeogr. Palaeoclimatol. Palaeoecol. 248, 391430.

Meyers, S.R., Sageman, B.B., Arthur, M.A., 2012. Obliquity forcing of organic matter accumulation during Oceanic Anoxic Event 2. Paleoceanography 27, PA3212, doi:10.1029/2012PA002286.

Moussine-Pouchkine, A., Seguret, M., Atrops, F., Amard, B., 1998. Lithochronostratigraphie à haute résolution dans le Kimméridgien du Bassin du Sud-Est: implications sur les taux de sédimentation et la durée des unités biostratigraphiques. $2^{\text {ème }}$ congrès Français de Stratigraphie, Paris, p 125.

Ogg, J.G., Ogg, G., Gradstein, F.M., 2008. The Concise Geologic Time-Scale, Cambridge University Press, 184 p.

Pälike, H., Norris, R.D., Herrle, J.O., Wilson, P.A., Coxall, H.K., Lear, C.H., Shackleton, N.J., Tripati, A.K., Wade, B.S., 2006. The Heartbeat of the Oligocene Climate System. Science 314, 1894-1898.

Pederneiras, R.G., 1995. Stratigraphie et faciès de tempète de la rampe carbonatée du Jurassique supérieur du 
centre du Bassin du Sud Est (France): calcarénites, brèches, corps glissés. PhD thesis, Univ. Montpellier II, $239 \mathrm{p}$.

Taner, M.T., 2000. Attributes Revisited, Technical Publication. Rock Solid Images, Inc., Houston, Texas. URL: http://www.rocksolidimages.com/pdf/attrib_revisited.htm.

Thomson, D.J., 1982. Spectrum estimation and harmonic analysis. IEEE Proc. 70, 1055-1096.

Torres, M.E., Brumsack, H.J., Bohrmann, G., Emeis, K.C., 1996. Barite fronts in continental margin sediments: A new look at barium remobilization in the zone of sulfate reduction and formation of heavy barites in diagenetic fronts. Chemical Geology 127, 125-139.

Westerhold, T., Röhl, U., Laskar, J., Raffi, I., Bowles, J., Lourens, L.J., Zachos, J.C., 2007. On the duration of Magnetochrons $\mathrm{C} 24 \mathrm{r}$ and $\mathrm{C} 25 \mathrm{n}$, and the timing of early Eocene global warming events: Implications from the ODP Leg 208 Walvis Ridge depth transect. Paleoceanography 22(PA2201): doi:10.1029/2006PA001322. 
2 Climatic precession is the main driver of Early Cretaceous sedimentation in the

3 Vocontian Basin (France): evidence from the Valanginian Orpierre succession

4

5

6

7

8

9

10

11

12

13

14

15

16

Slah Boulila*, Guillaume Charbonnier, Bruno Galbrun, and Silvia Gardin

* Corresponding author:

Email address: slah.boulila@upmc.fr

Telephone number: 0033 (0)144274163

Fax number: 0033 (0) 144273831

Supplementary Figure S1: Sampling steps adopted for the cyclostratigraphic studies of the upper Valanginian sections (SE France) by (A) Martinez et al. (2013) at Reynier-Angles (RA) and Vergol-Morénas-La Charce (VMC) composite sections, and (B) Charbonnier et al. (2013) at Orpierre section.
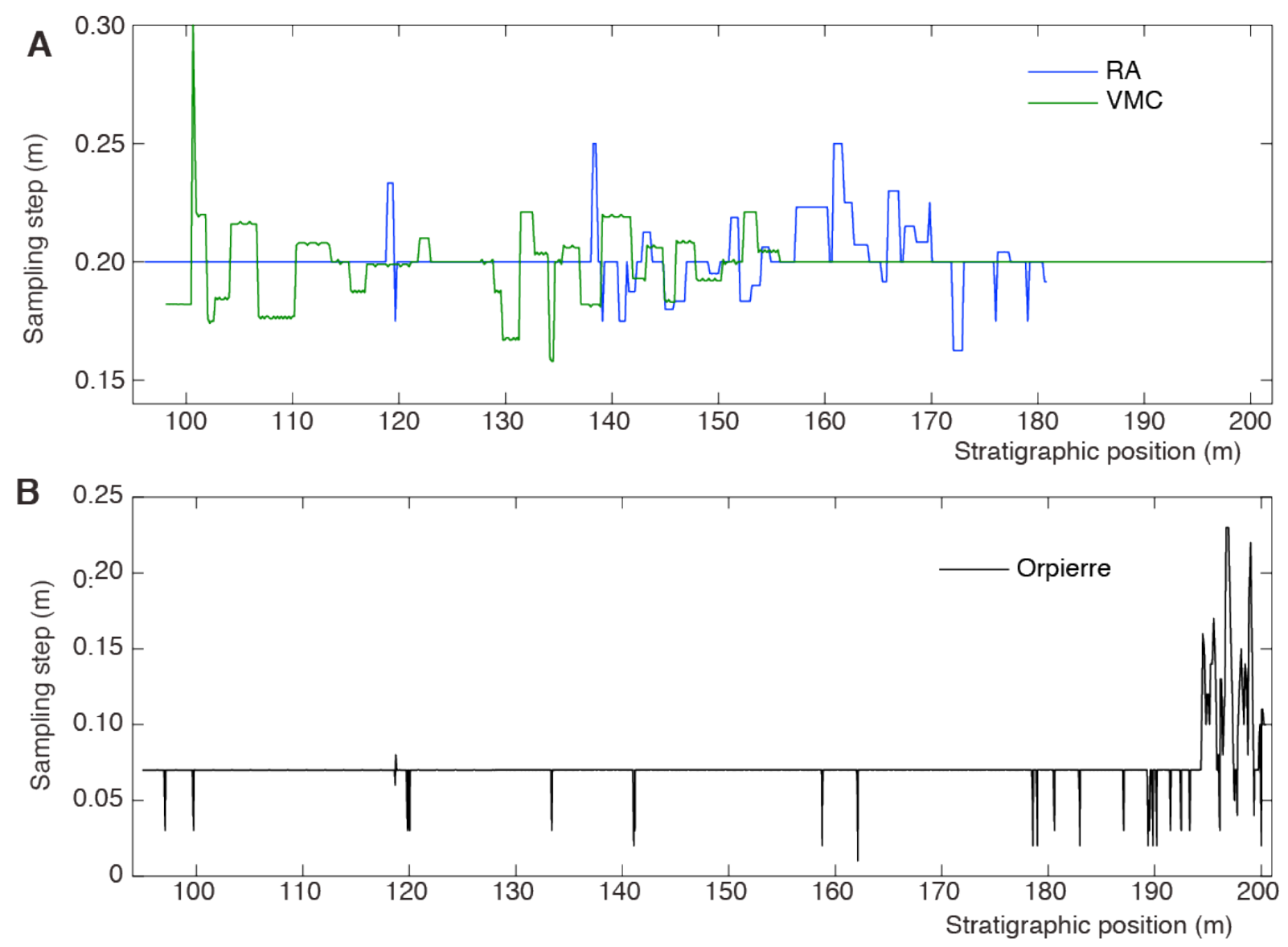

18 Supplementary Figure S2: Details on counting of precession cycles and their relationship 19 with the main-primary and secondary (diagenetic?) marl-limestone couplets at the Orpierre 
20 section (data are from Charbonnier et al., 2013). Question marks indicate poorly constrained 21 precession cycles. Our methodology to interpret precession cycles is based on MS 22 amplitudes (i.e., carbonate content). We have noted that precession cycles sometimes 23 correspond to the couplets, and sometimes do not match the couplets.

24 We suggest that this mismatch may be the result of additional limestone beds with lower 25 carbonate contents (where there are more than one couplet), possibly of a seconday 26 (diagenetic?) origin or may be due to another unknown origin (autocyclic factors, high27 frequency climatic variability, etc). Also, we note well-expressed precession cycles within 28 apparently homogeneous marls. This shows the potential of the use of highly resolved 29 physical proxies for the detection of astronomical frequencies, undetectable by classic 30 stratigraphic methods (e.g., field observation).

31 Note that in the main manuscript we have sometimes used the term "couplets" to simply 32 indicate precession cycles controlling the main couplets (i.e., with higher carbonate 33 contents). 
Figure S2 (Page 1/3)

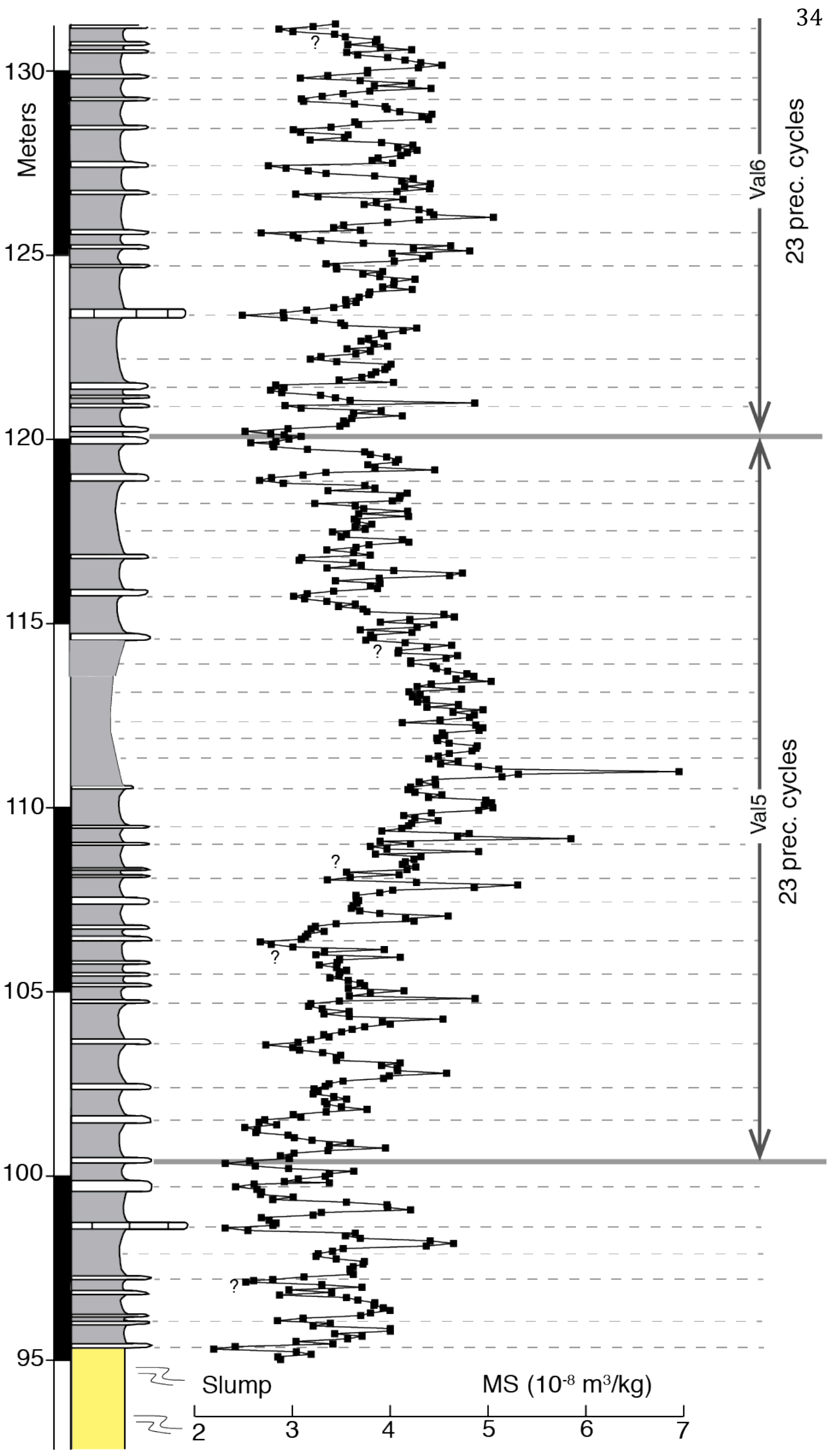


Figure S2 (Page 2/3)

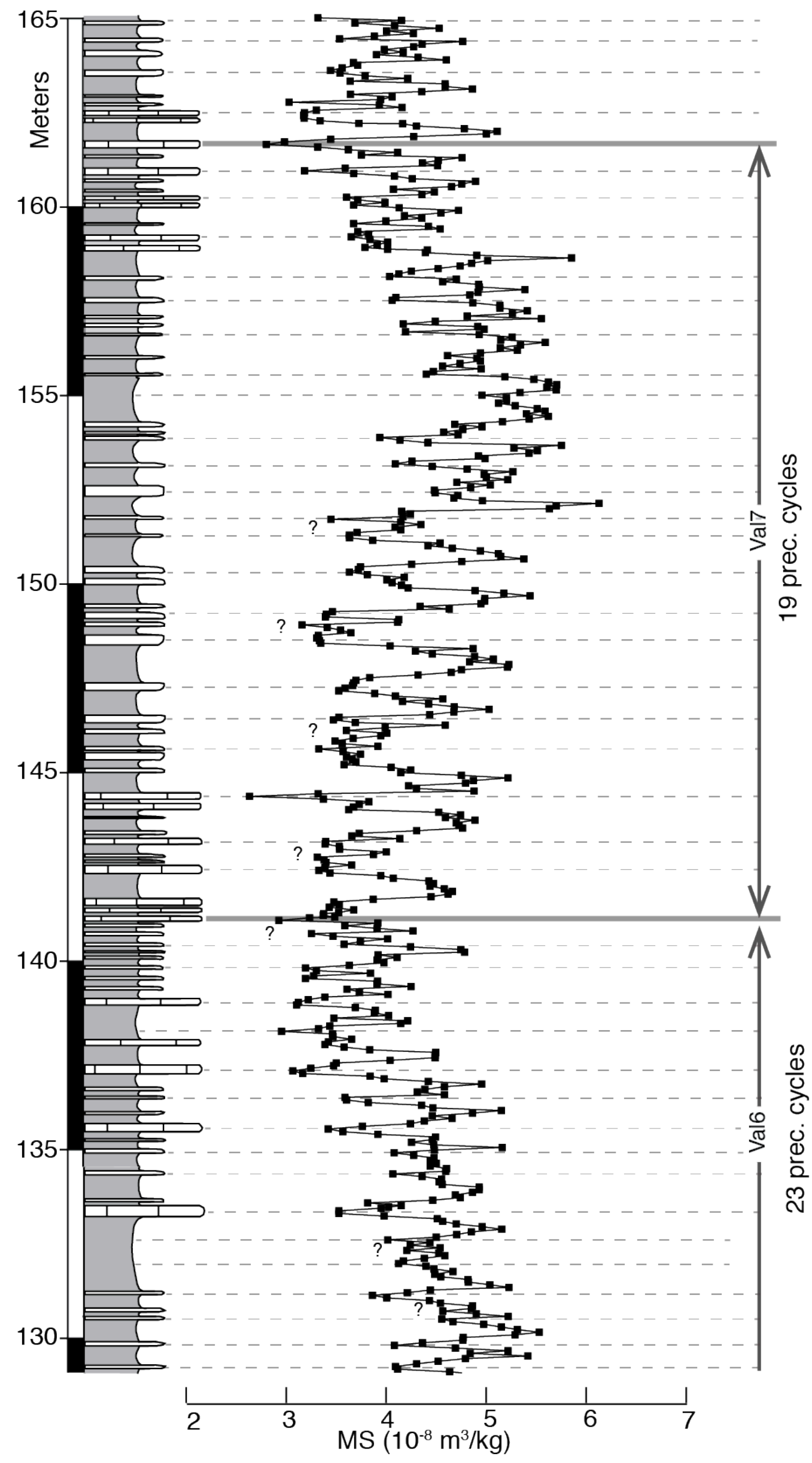


Figure S2 (Page 3/3)

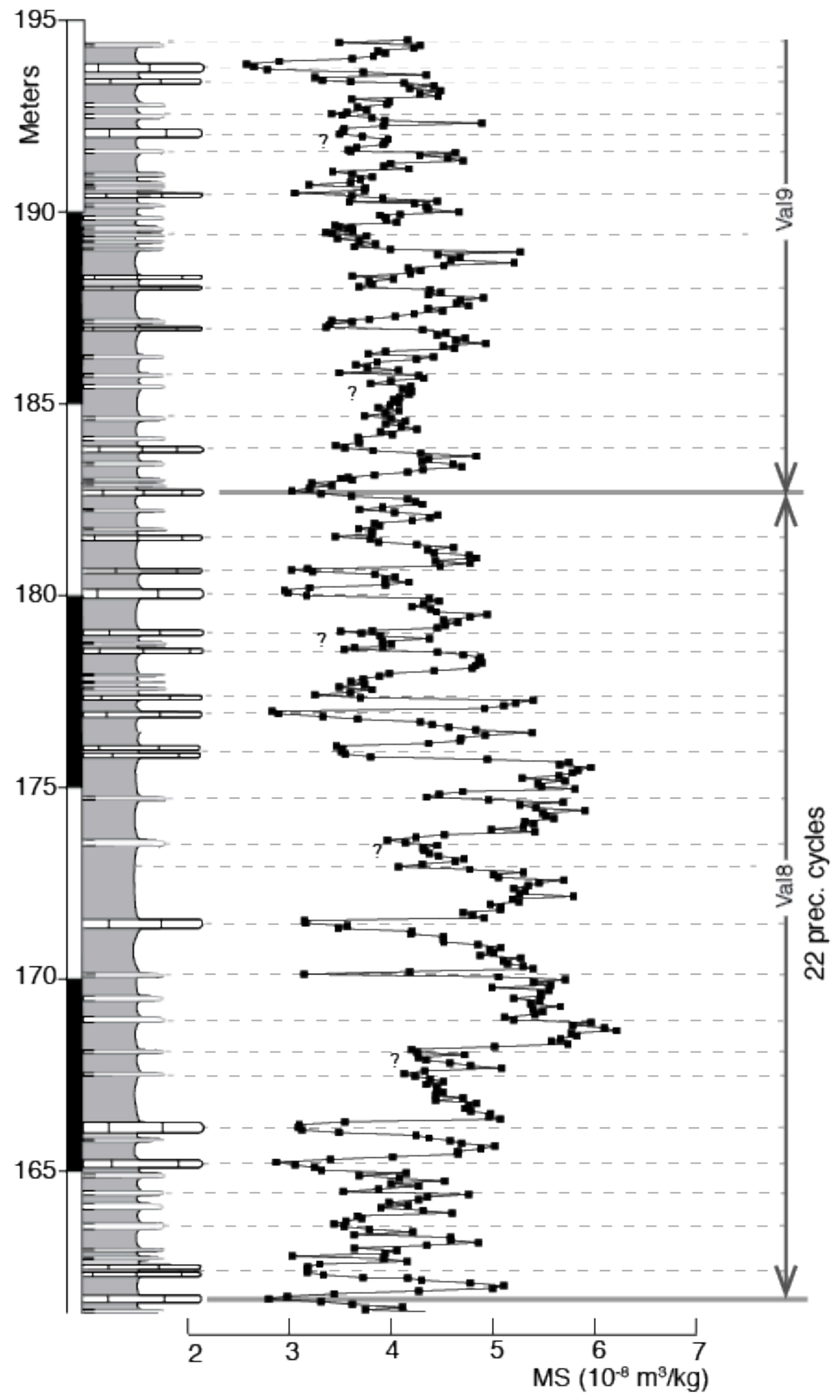


37 Supplementary Figure S3: Details on counting of precession cycles and their relationship 38 with the main-primary and secondary (diagenetic?) marl-limestone couplets at Reynier39 Angles (RA) composite section (data are from Martinez et al., 2013). Captions and notes are 40 as in Figure S2. The shaded interval spanning V9, V10 and V11 corresponds to that in which 41 Martinez et al. (2013) have interpreted the couplets as obliquity in origin. Note that V9, V10 42 and V11 cycles are poorly constrained. 
Figure S3 (Page 1/2)

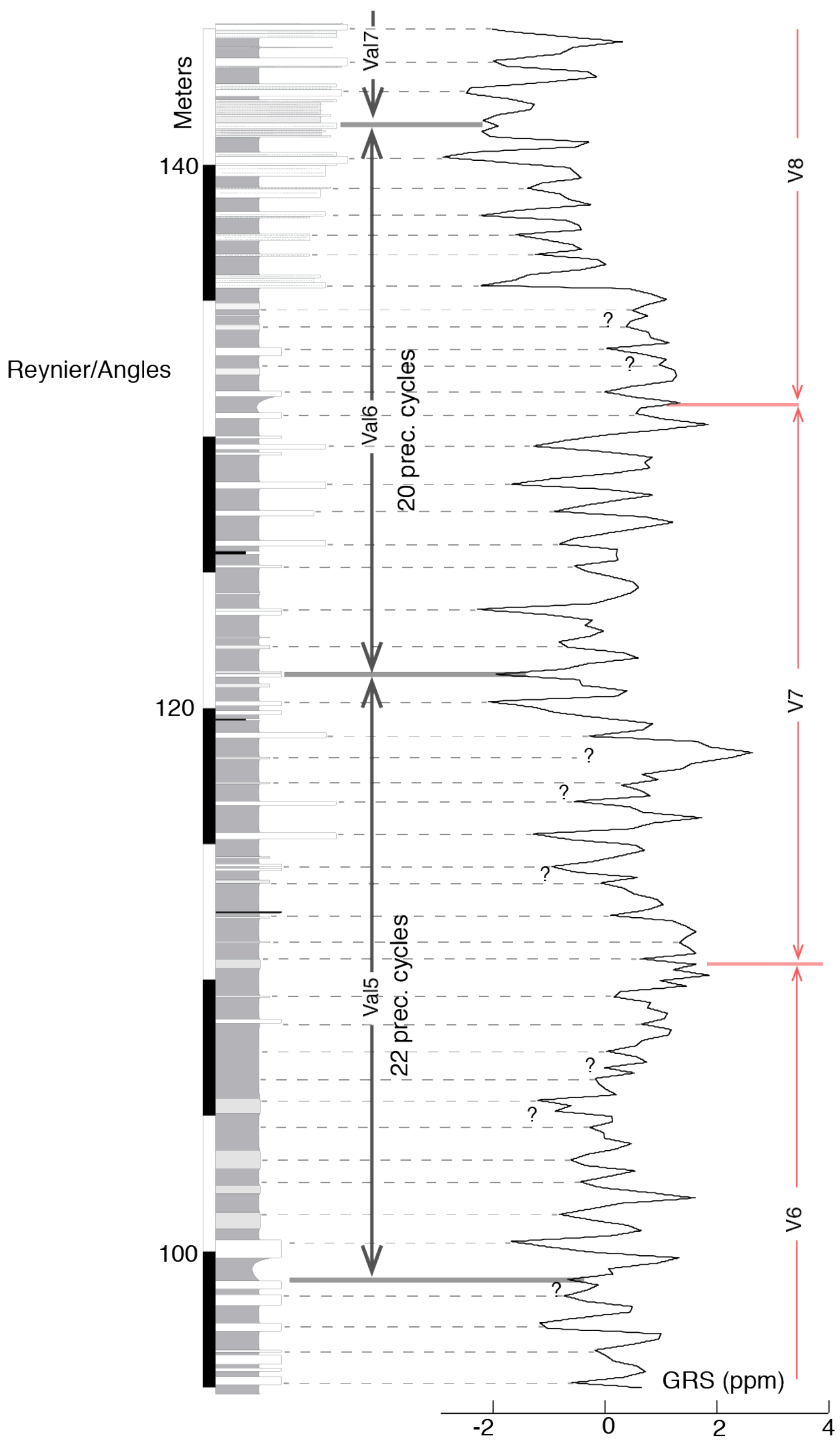


Figure S3 (Page 2/2)

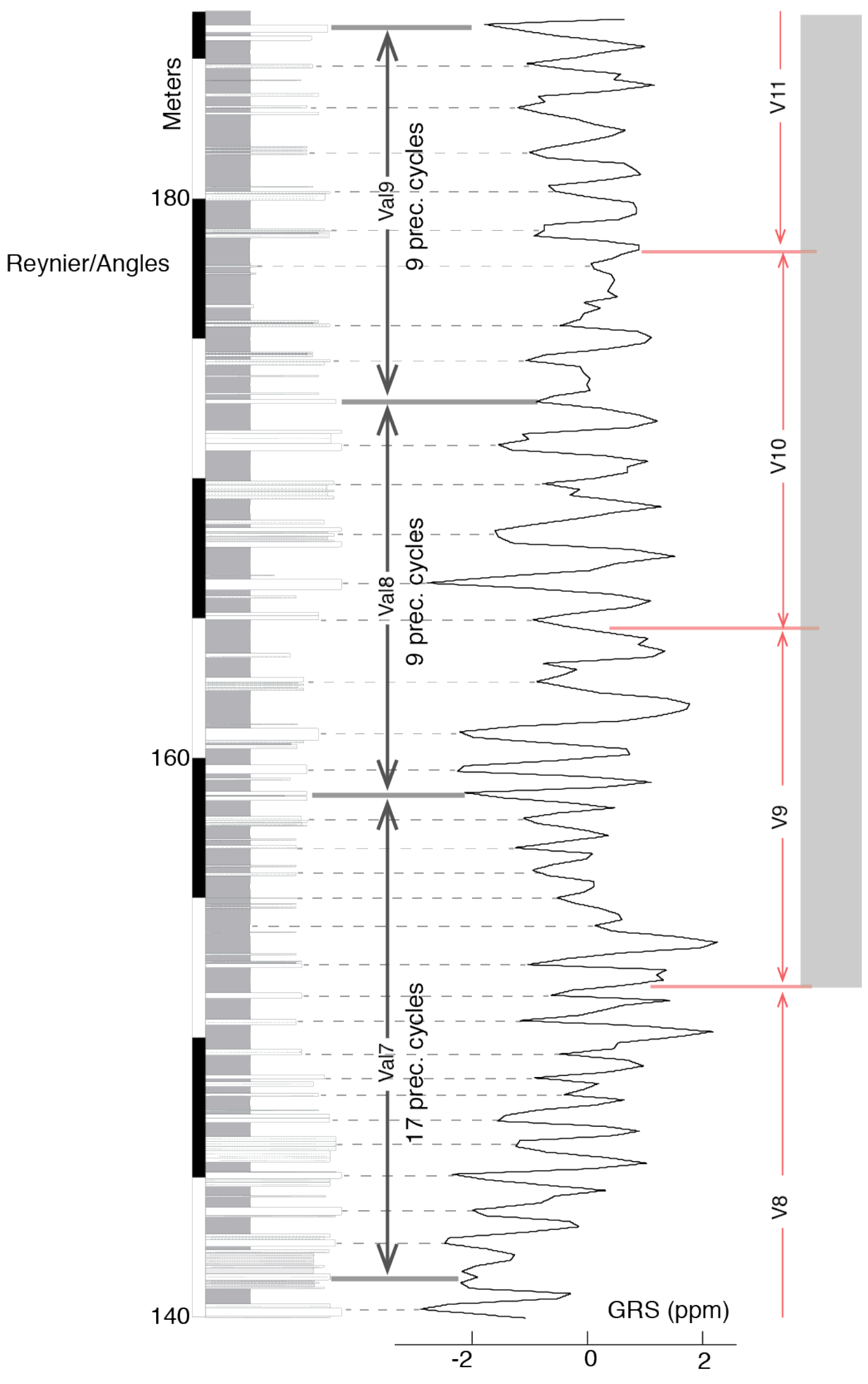


45 Supplementary Figure S4: Details on counting of precession cycles and their relationship 46 with the main-primary and secondary (diagenetic?) marl-limestone couplets at Vergol47 Morénas-La Charce (VMC) composite section (data are from Martinez et al., 2013). Captions 48 and notes are as in Figure S2. The shaded interval spanning V9, V10 and V11 corresponds 49 to that in which Martinez et al. (2013) have interpreted the couplets as obliquity in origin. 50 Note that $\mathrm{V} 9, \mathrm{~V} 10$ and $\mathrm{V} 11$ cycles are poorly constrained. 
Figure S4 (Page 1/2)

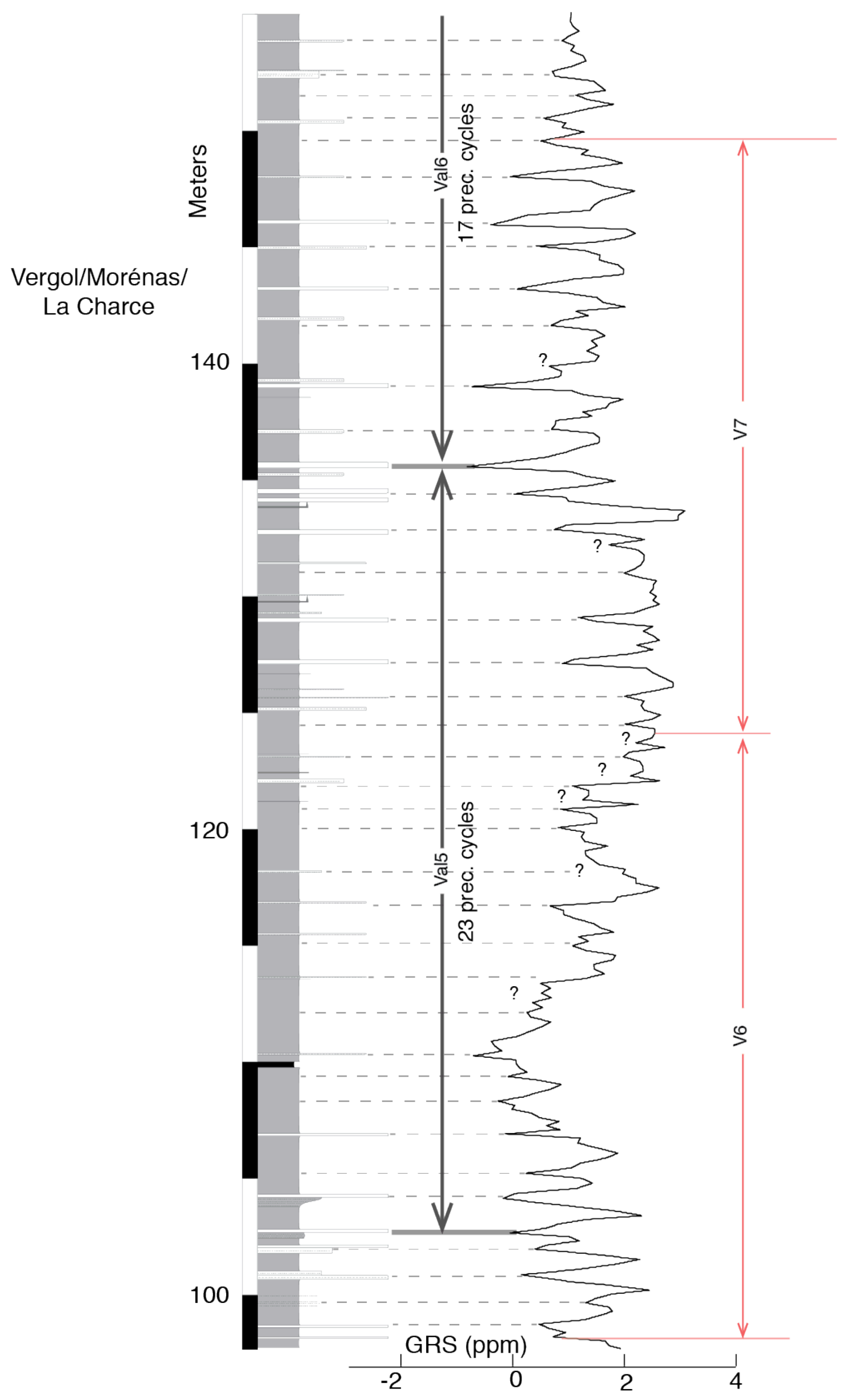


Figure S4 (Page 2/2)

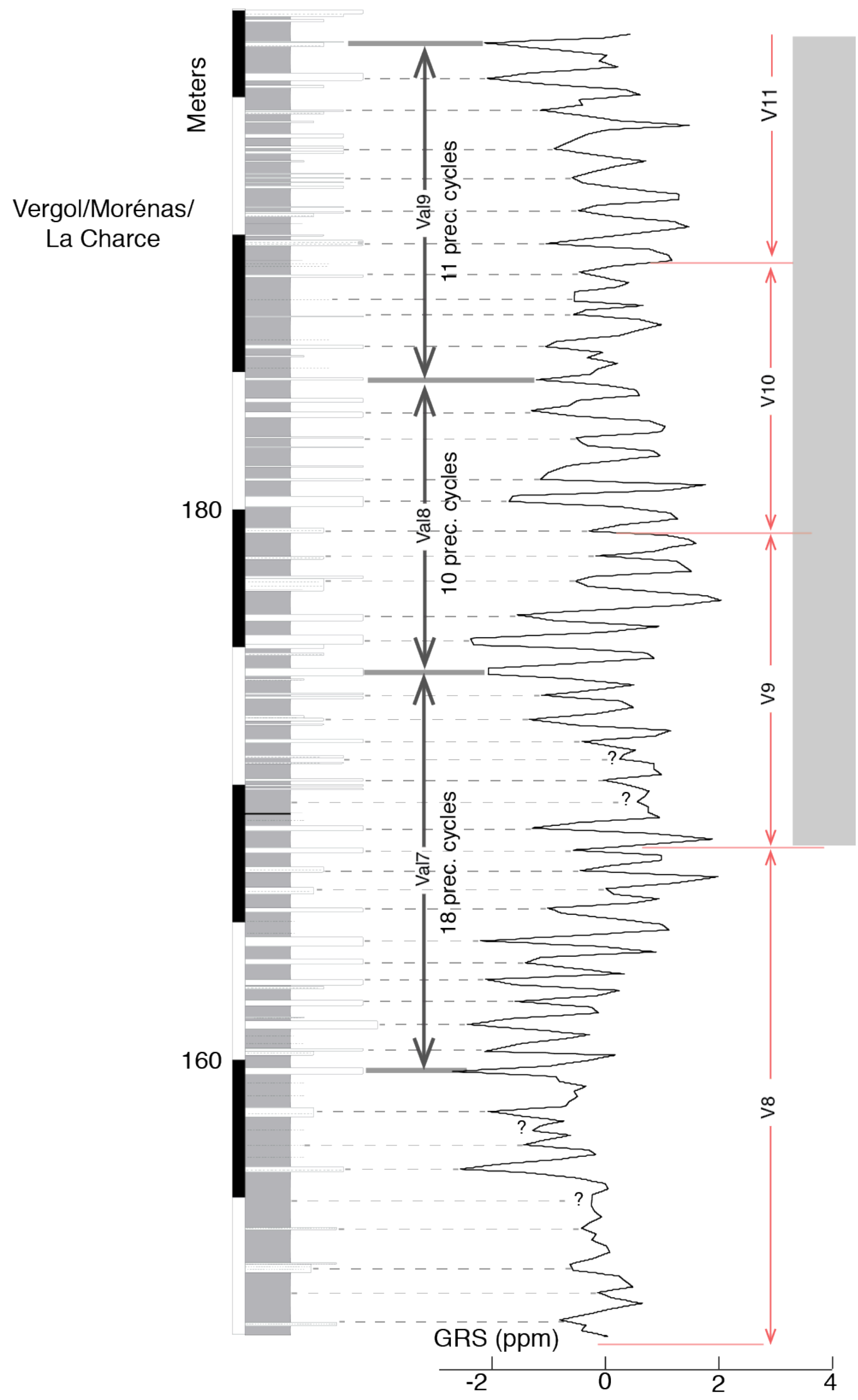

